
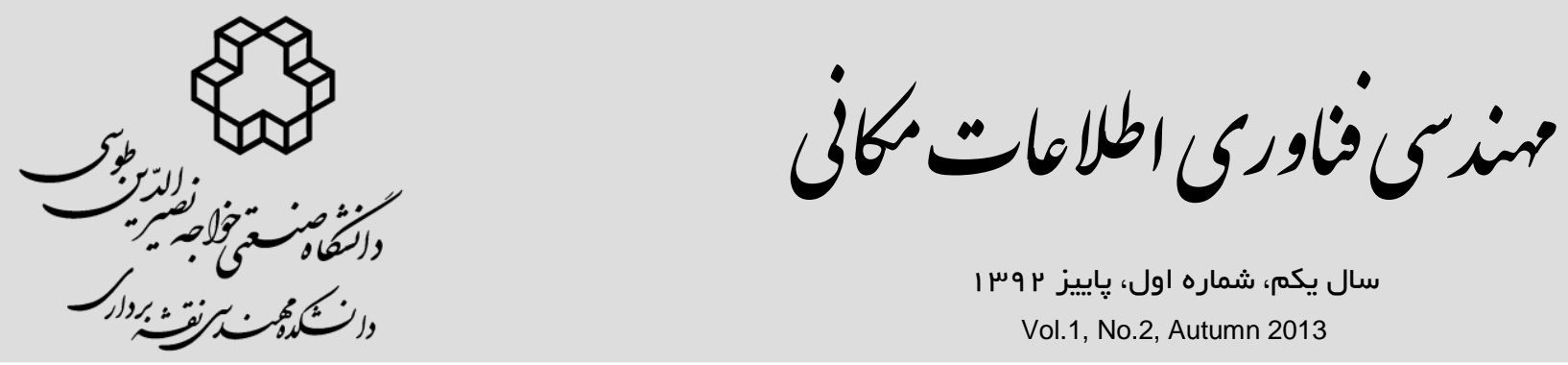

سال يكمر، شماره اول، ياييز ر وسر

Vol.1, No.2, Autumn 2013

\author{
تعيين الكوى تغيير شكل ارتفاعى سطح يوسته زمين در فلات ايران

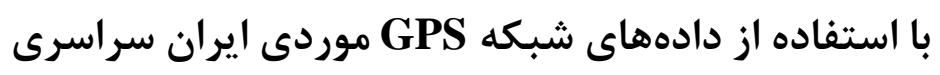 \\ مسعود مشهدى حسينعلى *'، حميدرضا حيدرى \\ 1 - استاديار دانشكده مهندسى نقشهبردارى، دانشعاه صنعتى خواجه نصيرالدين طوسى

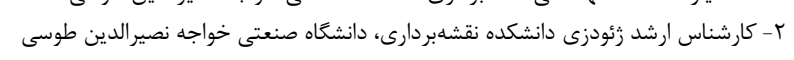 \\ تاريخ دريافت مقاله: I//N/|
}

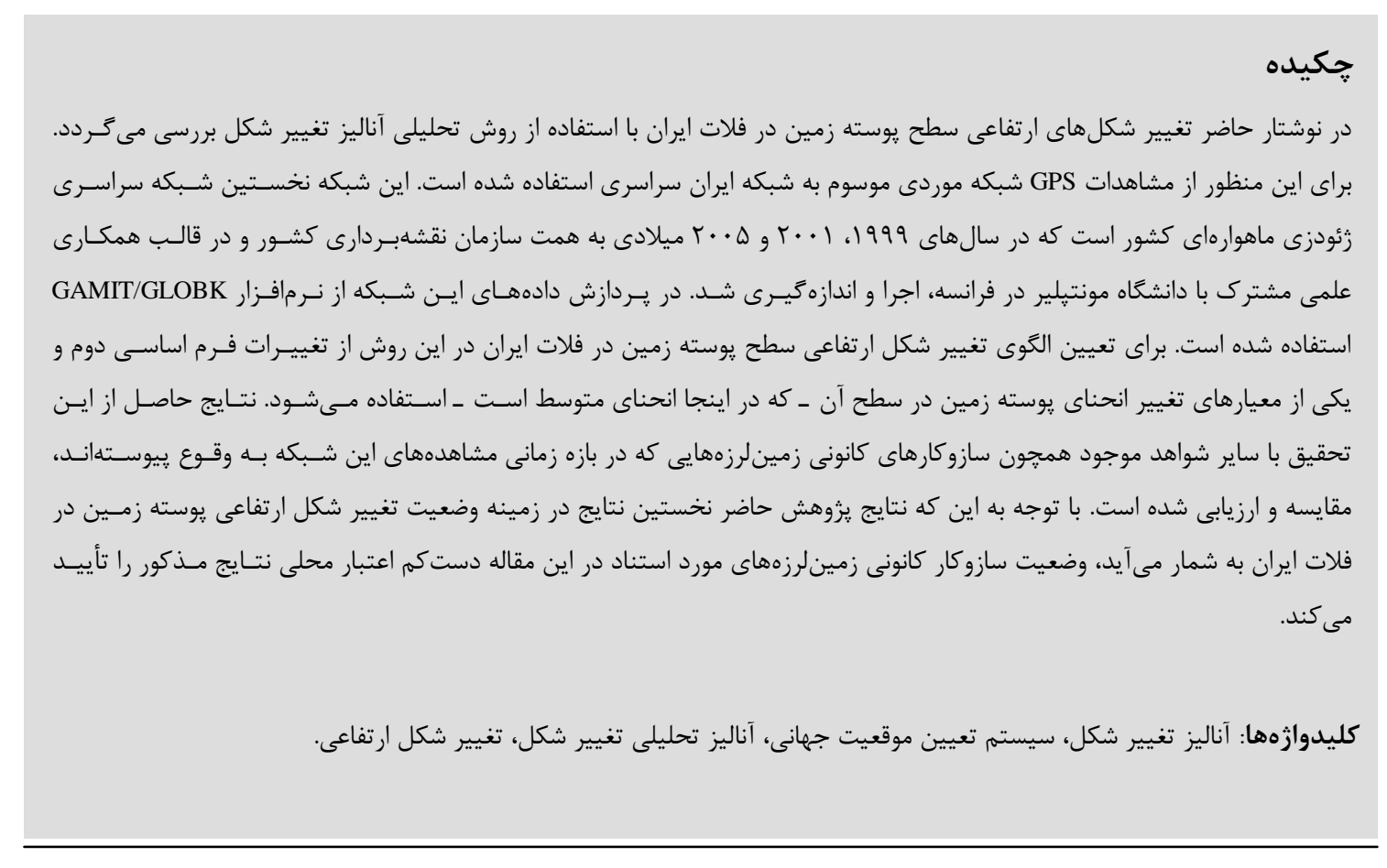

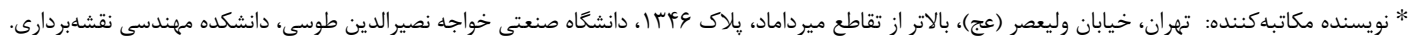




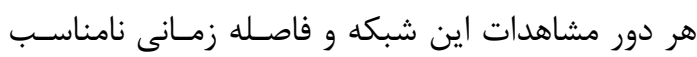

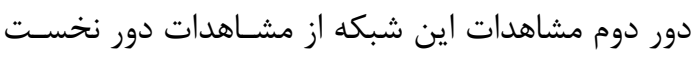

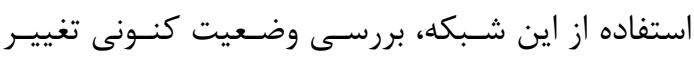
شكل ارتفاعى در كشور را ناممكن مىنمايد.

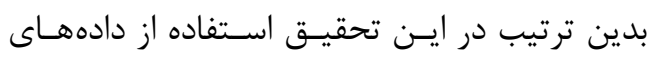

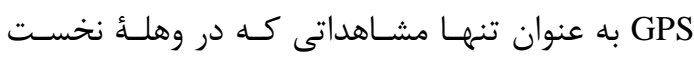

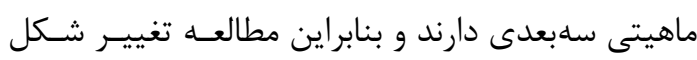

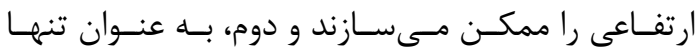

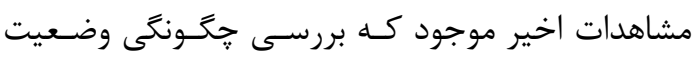

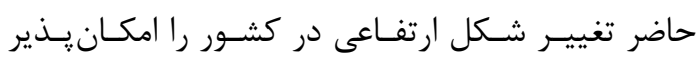

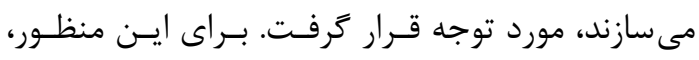
دادههاى شبكه GPS موردى ايران سراسرى از سـازمان

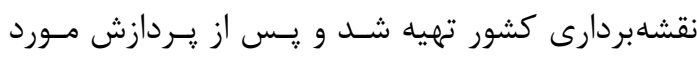
تجزيه و تحليل قرار كرفت. اين دادها و جزئيات مربوط

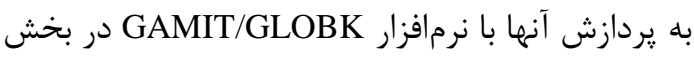

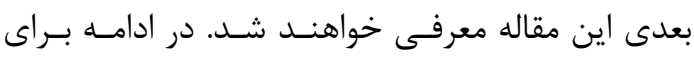

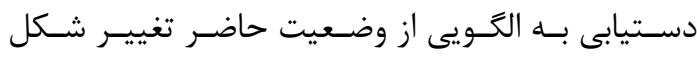

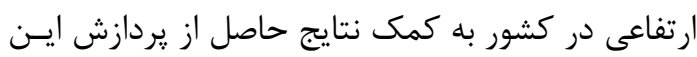
مشاهدات، از تئورى تحليلى آناليز تغيير شكل اسـتفاده

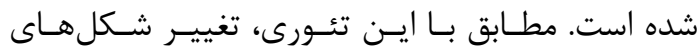

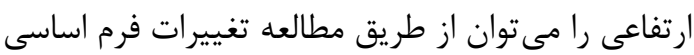

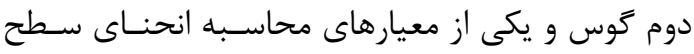

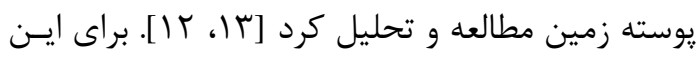
منظور در اين مقاله از معيار انحنــاى متوسـط اسـتفاده شده است. در ادامه ضمن معرفى ايـن روش، جزئيـات مربوط به نتايج به دست آمده ارائه مى خـردد و بـا سـاير

$$
\text { شواهد موجود ارزيابى و مقايسه مىشود. }
$$

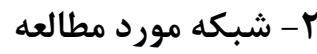

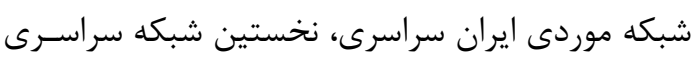

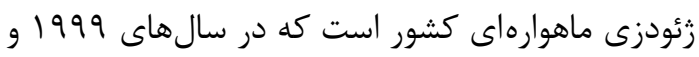

1. Seismic Deformation

2. Aseismic Deformation
| - 1- مقدمه

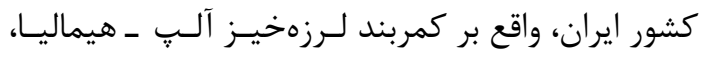

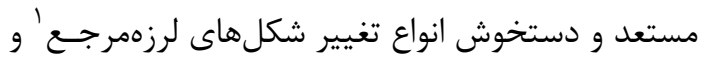

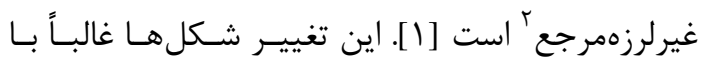
مؤلفههاى مسطحاتى بزركى (در حد دقت سيستمهـاى

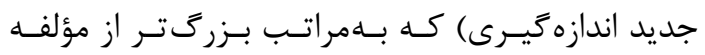

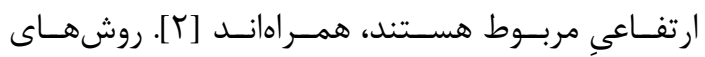

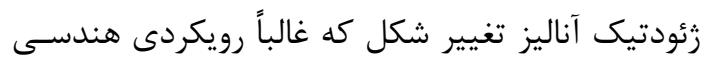

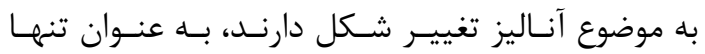

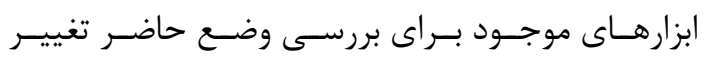

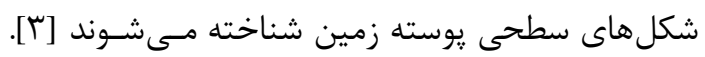

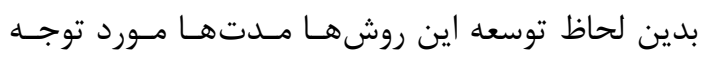

متخصصان ذىربط بوده است [N، V، צ، ه، ؟4]. براساس بررسى هاى بهعمل آمـده در ايـن تحقيـق، تاكنون در ايران مطالعه تغيير شكلهاى سطحى يوسته

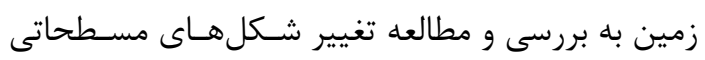
محدود شده است. بنابراين مقاله حاضر نخستين تحقيق در زمينه مطالعه تغيير شـكل ارتفــاعى در فـلات ايــان بلهمار مى آيد. كوخكتر بـودن مؤلفـهـ ارتفـاعى تغييـر

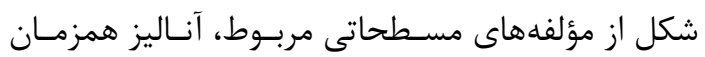

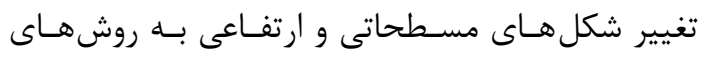

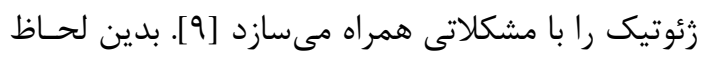

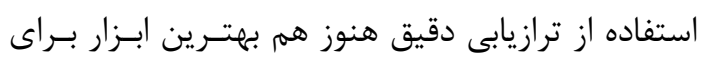

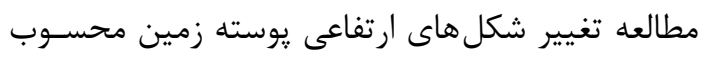

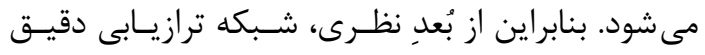

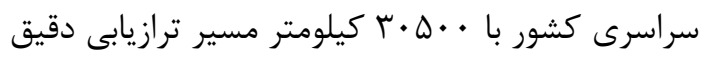

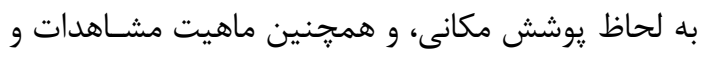

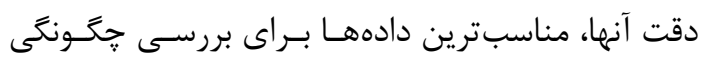

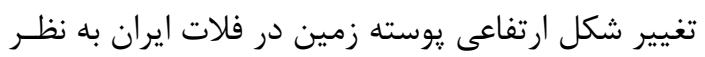

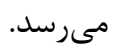

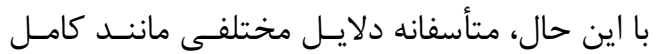

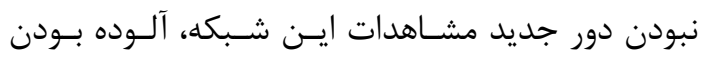

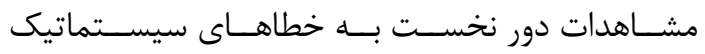
[1 ا و • []]، مدت زمان بسيار طولانى لازم بـراى انجـام 


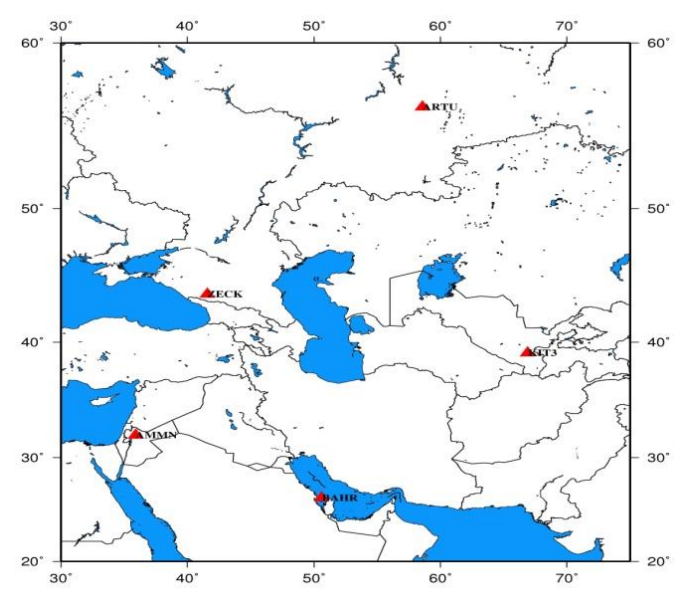

شكل r. ايستخاههاى GNSS مورد استفاده در يردازش

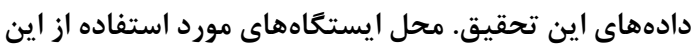

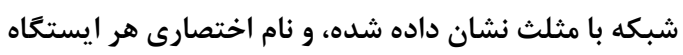

در كنار محل هر ايستگاه به نمايش در آمده است.

r-1 - مشاهدات شبكه ايران سراسرى.

r 1999 1-1- مشاهدات سال

مشاهدات اين سال در 11 1 روز متوالى انجام شده اسـت.

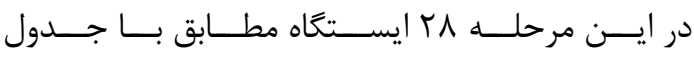

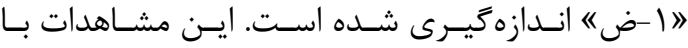

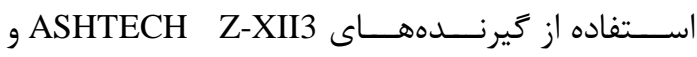
TRIMBLE 4000SSI ASH701945B-M

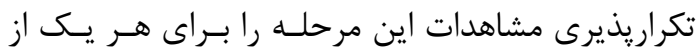

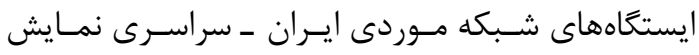

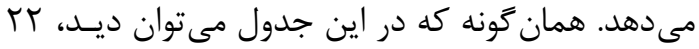

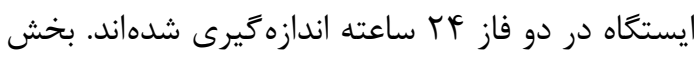

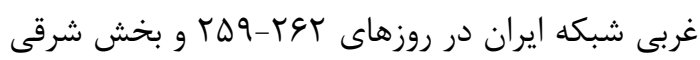

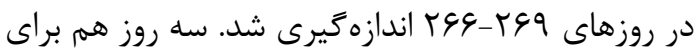
جابهجايى گيرندها و تيمهاى مشاهداتى بين دو فاز در

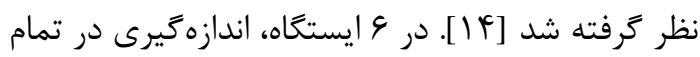

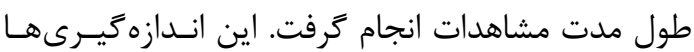

1. International GNSS Service for Geodynamics 2. Scripts Orbit and Permanent Array Center

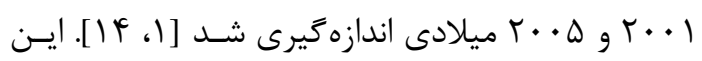
شبكه متشكل از ^ץ ايسـتخاه مــوردى GPS اسـت كـهـ

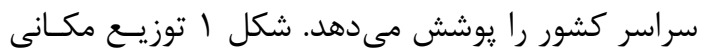
نقاط اين شبكه را نشان مى دهد. مشاهدات ايـن شـبكه روبـ در روزهـاى أY

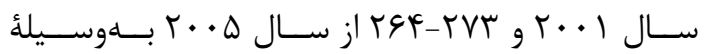
سازمان نقشهبردارى انجام شده است.

به منظور اتصـال ايسن شـبكه بـه شـبكه 'IGNSS'

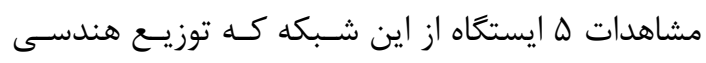

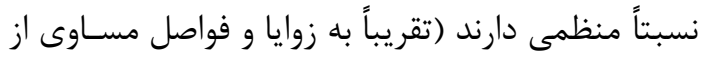
مركز ايران)، از طريق سرويس 'SOPAC دريافت شد و به همراه مشاهدات اين شبكه يردازش گرديد. اسـتفاده از ايســخاههــاى شـبكه IGNSS در يــردازش، امكــان استفاده از موقعيت و سـرعت حركـت ايـن نقـاط را در فريم ITRF فراهم مىسازد و در نتيجه مشكل سيسـتم مختصات را در برآورد ميـدان سـرعت مرتفـع مسى كنـد [1ه]. شكل ب توزيع مكانى ايستخاههاى IGNSS مــورد استفاده در اين تحقيق رانشان مىدهد.

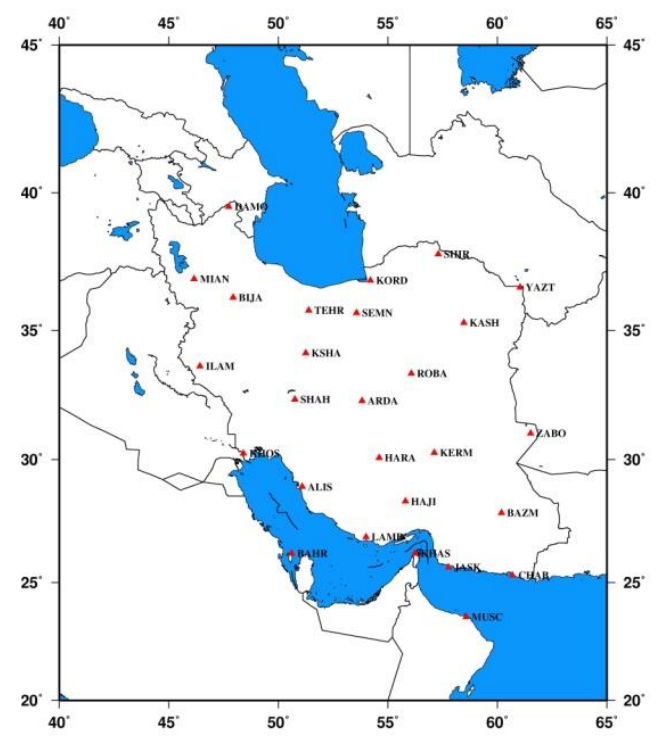

شكل ا. ايستخاههاى GPS موردى شبكه موسوم به ايران سراسرى. نام اختصارى هر ايستخاه در كنار محل ايستخاه نمايش داده شده است. 


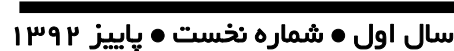

ايسـتكاههـاى شــبكه مـوردى ايـران سراسـرى نمـايش

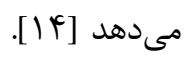

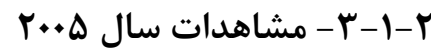

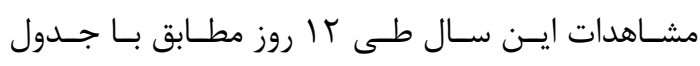

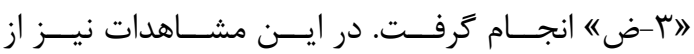
كيرنسـهــــ ASHTECH Z-XII3 ASHTECH UZ-12, 4000SSI ASH701945B_M استفاده شده است. در اين مرحلـه

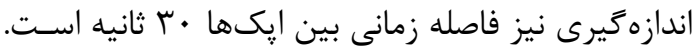

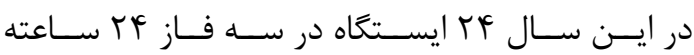
اندازه كيرى شدند كه سهم هر فاز 1 ايستكاه بوده است.

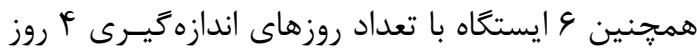
يا بيشتر براى اتصال اين ب فـاز در نظـر كرفتـه شـدند.

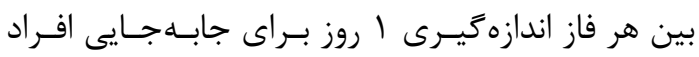
ذى بربط و وسايل اندازهيرى در نظر كرفته شد. جدول ״ب-ض" تكراريذيرى مشاهدات ايـن مرحلـه

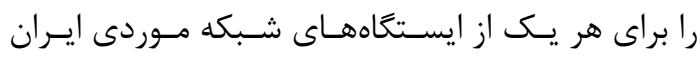
سراسرى نمايش مى دهد.

\section{T- بردازش دادهها با نرمافزار GAMIT}

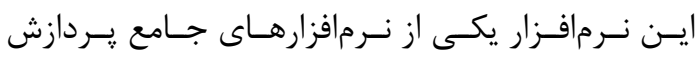

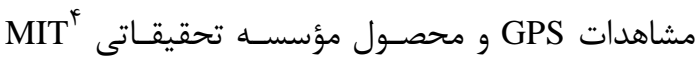

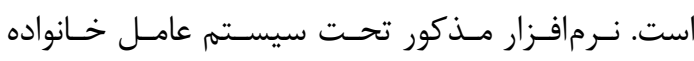

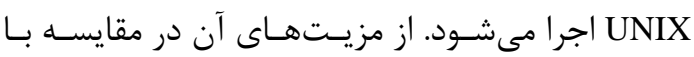

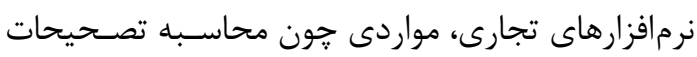
مربوط به يارامترهاى مدارى، تصحيحات مربوط به جزي تران

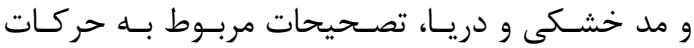

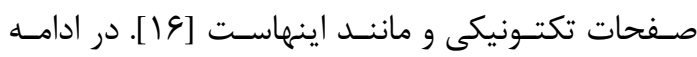

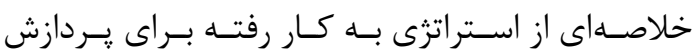
مشاهدات به كمك اين نرمافزار ارائه مىشود.

1. Cut of angle

2. Self centering (Pillar)

3. Tripod

4. Massachusetts Institute of Technology

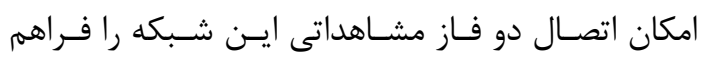

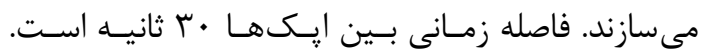
همجنين براى اجتناب از خطاى جندمسـيرى، حـداقل

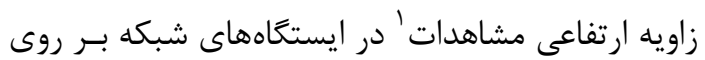

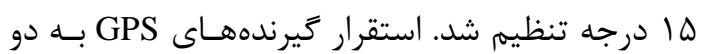

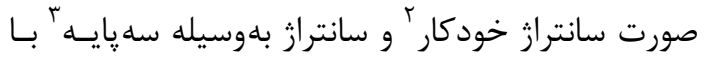

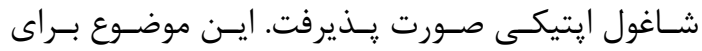

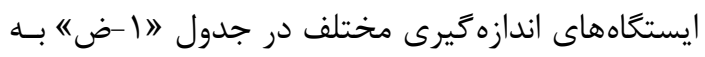

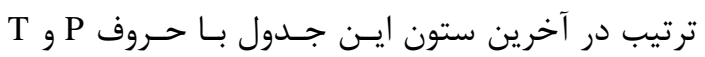
مشخص شده است [If

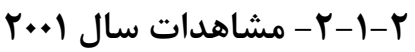

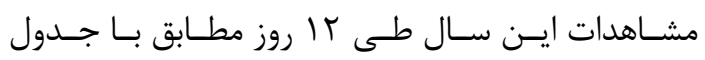
״ץ-ض" انجام كرفت. اين مشاهدات نيز بـا اسـتفاده از TRIMBLE 4000SSI， ASHTECH Z-XII3 كيرندان ASHTECH UZ-12

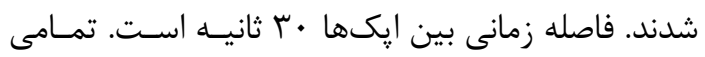

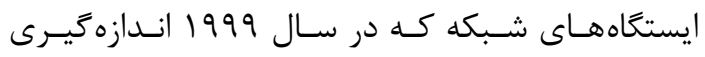

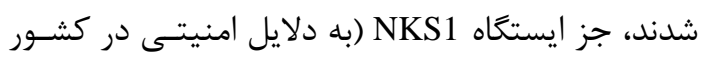

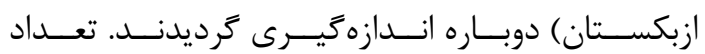

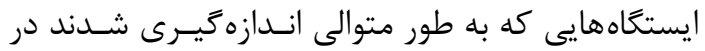

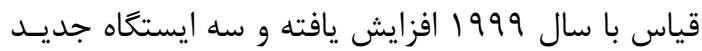
به شبكه ايران سراسرى افزوده شده است. بخش غربسى

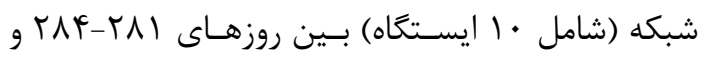

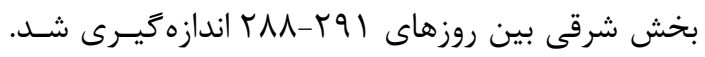

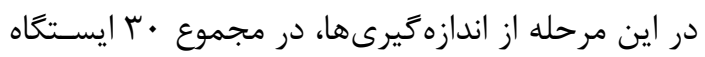

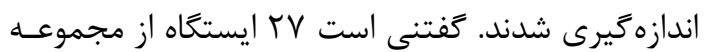

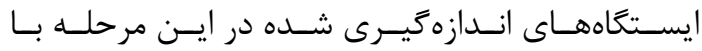

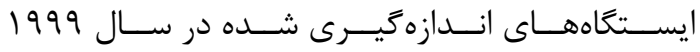

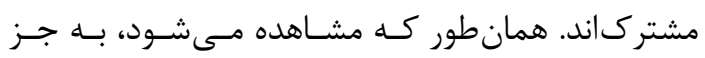

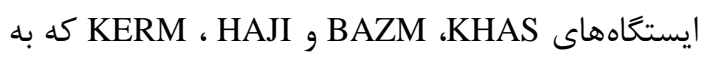
ترتيب سه و دو روز اندازهكيرى شدند، ساير ايستخاههـا

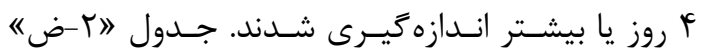

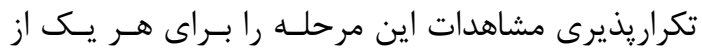




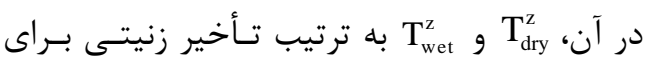

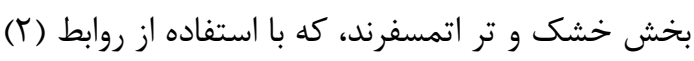

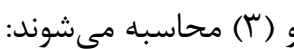
$\mathrm{T}_{\mathrm{dry}}^{\mathrm{z}}=10^{6} \mathrm{KRP} / \mathrm{g}_{\mathrm{m}}$

رابطه (r)

$\mathrm{T}_{\mathrm{wet}}^{\mathrm{z}}=0 / 002277(1255 / \mathrm{T}+0 / 05) \mathrm{e}$

(ب) رابطه

در اين روابط K ضريب شكست، R ثابت كازها براى

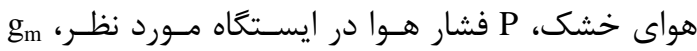

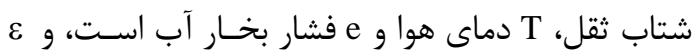
زاويه ارتفاعى ماهوارهاى است كه از ايستكاه مــورد نظـــ

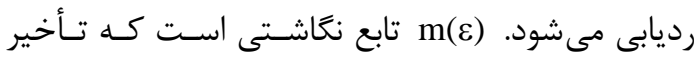

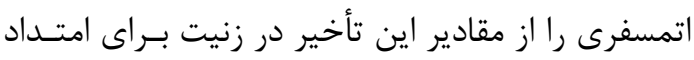

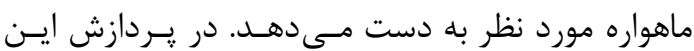

دادها از تابع نكاشت نيل استفاده شده است [19]

$$
\mathrm{m}(\varepsilon)=\frac{1+\frac{\mathrm{a}}{1+\frac{\mathrm{b}}{1+\mathrm{c}}}}{\sin (\varepsilon)+\frac{\mathrm{a}}{\sin (\varepsilon)+\frac{\mathrm{b}}{\sin (\varepsilon)+\mathrm{c}}}}
$$

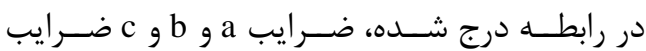

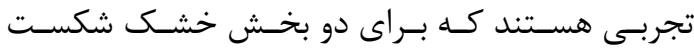

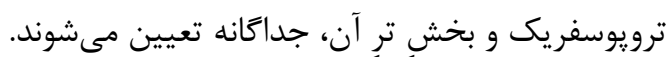

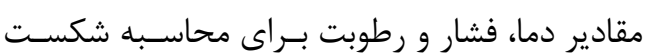

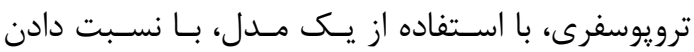

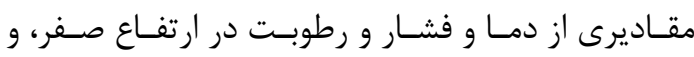

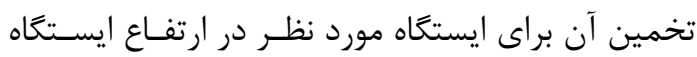

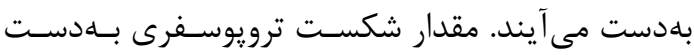

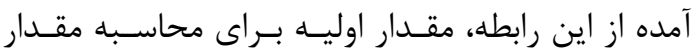

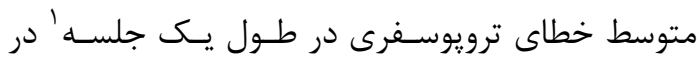
سرشكنى است. همجنين تغييرات خطاى ترويوسفرى از دروس

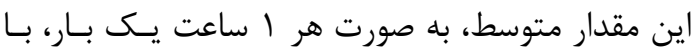

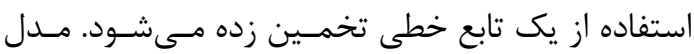

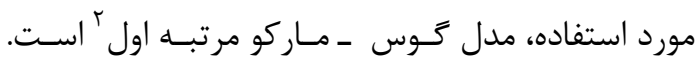

1. session

2. First order Gauss Markov process
در تعيين موقعيت با سيستم GPS، ماهوارهها نقـش

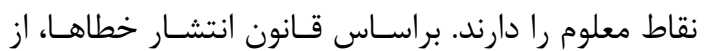
آنجا كه خطاى موقعيت نقاط معلوم مستقيماً بـهـ نقـاط

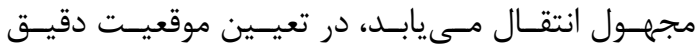

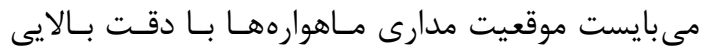

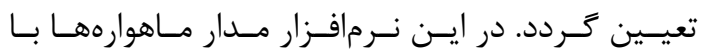

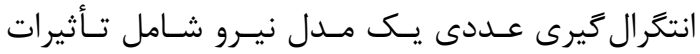
جاذبه ماه و خورشيد بر روى مـاهوارههـا، مــدل ميـدان جاذبه زمين (IGS92) و همجنين يك مدل 9 و يارامترى روى

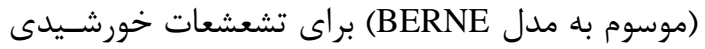
بلددست مى آيد [IV] با باستفاده از مقادير به دست آمده براى مدار ماهوارهها و مقادير اوليه مختصات ايستخاهها، و نيز با به كاركيرى يارامترهـاى دوران زمسين و مقــادير IAU76 يرسشن و نوتيشن محور دوران زمهين از مهدي

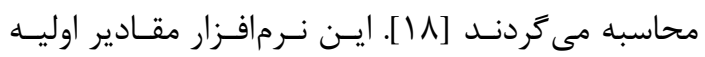

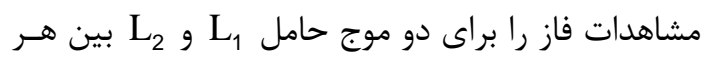

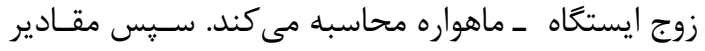

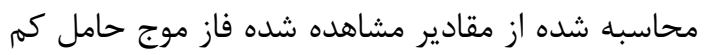

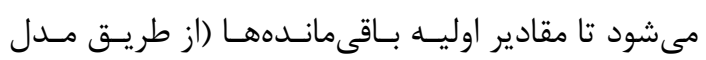

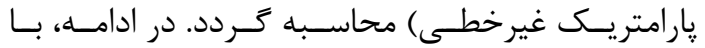

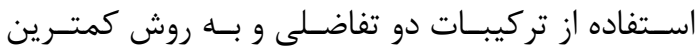

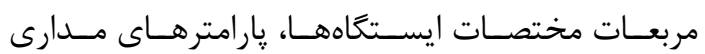

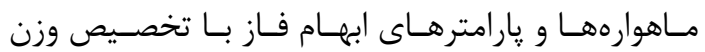

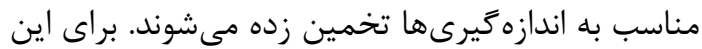

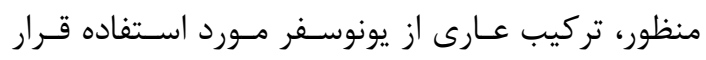

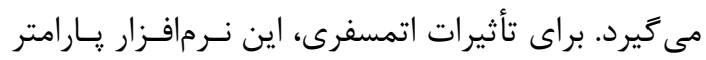
متوسطى را براى كل مدت اندازمخيرى تخمين مىزند و

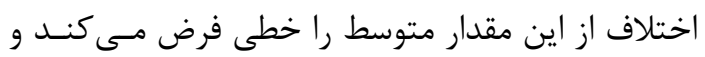

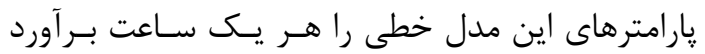
مى كند [91]]. در ايـن تحقيـق از مـدل Saastamoinen

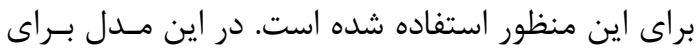
محاسبه خطاى اتمسفرى از رابطه ( ) استفاده مىشود:

رابطه (1)

$\operatorname{ATMDEL}(\varepsilon)=\mathrm{T}_{\text {dry }}^{\mathrm{z}} \times \mathrm{m}(\varepsilon)+\mathrm{T}_{\mathrm{wet}}^{\mathrm{z}} \times \mathrm{m}(\varepsilon)$ 


\section{سال اول • شماره نخست • ياييز م وس}

مشاهدات دوتفاضلى ״ّ يارامترهاى زئودتيكى و اتمسـفرى

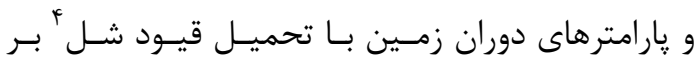

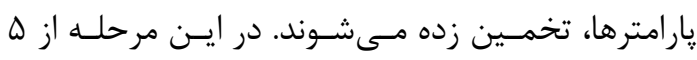

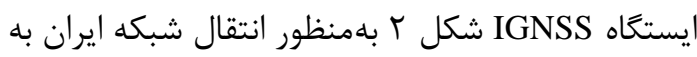
فريم مرجع ITRF 2000 استفاده شده است. در مرحله دوم بـا اسـتفاده از برنامـه كـالمن فيلتــر نتايج حاصل از يردازش روزانـه، بـه منظــور

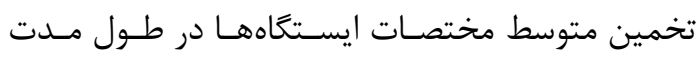

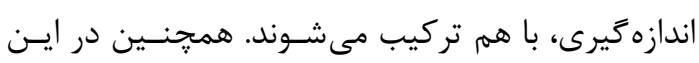

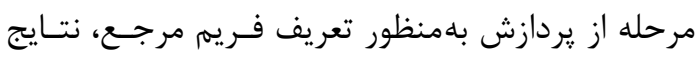

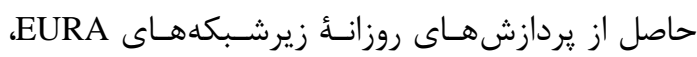
IGS1 ،IGS2 ،IGS3 از يردازش روزانه تركيب مىشود [سrr].

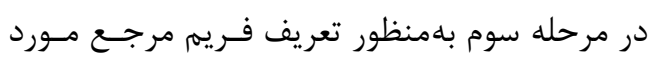
نياز براى تخمين ميدان سرعت شبكه ايـران، و يـارامتر

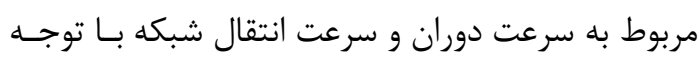

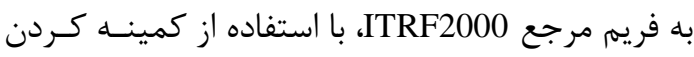
مجمــوع مربعـات تصــحيحات ســرعت · ل ايســتخاه IGNSS در سرشكنى مشاهدات فاز، وزندهيى بــه مشـاهدات بر اساس زاويه ارتفاعى ماهوارهها صورت يذيرفته است و

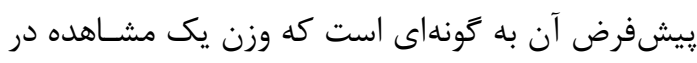

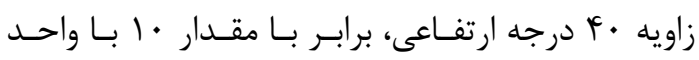

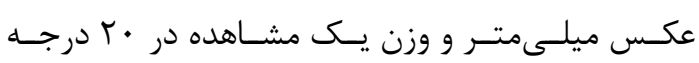
ارتفاعى برابر با نصف اين مقدار باشد [عابـــ

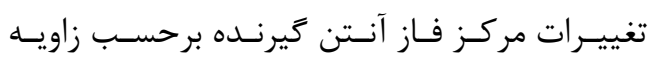

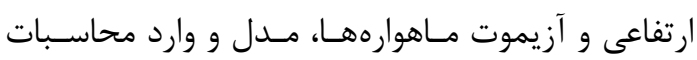

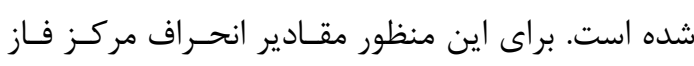

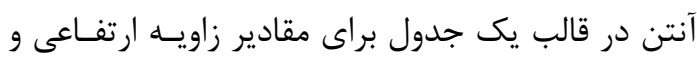

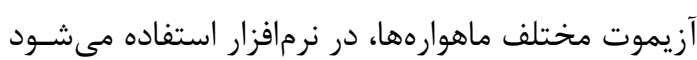

[19]

1. Correlation time

2. White noise

3. Double difference

4. Loosly constraint
به كار گيرى اين مدل باعث خواهد شد تا پييوستخى تـابع

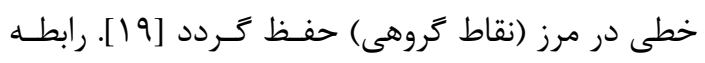
زير به رابطه گوس ـ ماركوف مرتبه اول معروف است:

$\frac{\mathrm{d} \Delta \nabla \mathrm{d}_{\text {Trop }}}{\mathrm{dt}}=\frac{-\Delta \nabla \mathrm{d}_{\text {Trop }}(\mathrm{t})}{\tau_{\mathrm{GM}}}+\mathrm{w}(\mathrm{t}) \quad$ (Q) در آن، $\tau$ زمـان وابسـتخى 'و w(t) خطـاى سـفيد

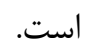
جواب اين معادله ديفرانسـيل بـدين صـورت اسـت

(9)

$\Delta \nabla \mathrm{d}_{\text {Trop }}(\mathrm{t}+\Delta \mathrm{t})=\mathrm{m} \Delta \nabla \mathrm{d}_{\text {Trop }}(\mathrm{t})+(1-\mathrm{m})^{\frac{1}{2}} \mathrm{w}(\mathrm{t})$ $\mathrm{m}=\exp \left(\frac{\Delta \mathrm{t}}{\tau}\right) \quad$ (V) همجنين گراديان شكست ترويوسـفرى جمعـاً بـــ

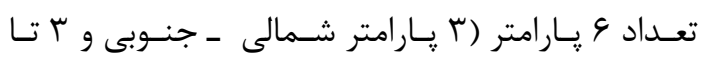
شرقى - غربى) براى هر ايستعاه در طول هـر جلسـه از يــردازش مشـاهدات تخمـين زده مـى شــود. ايسن كـار

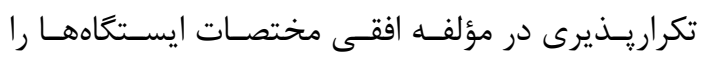

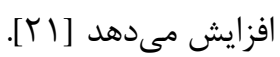

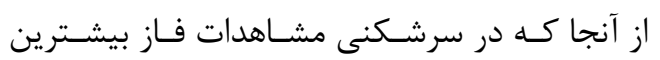

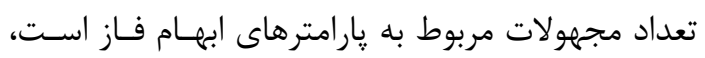
براى بهبود دقت نتايج سعى مىشود تا مقـادير صـحيح

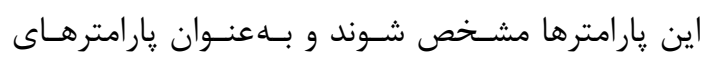

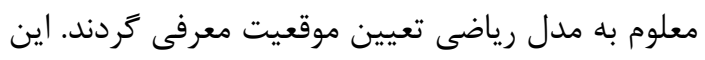

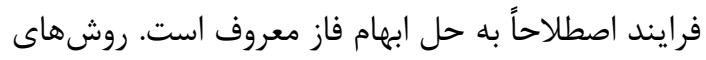
مختلفى براى حل ابهام مشاهدات فاز موج حامل وجــود إندام

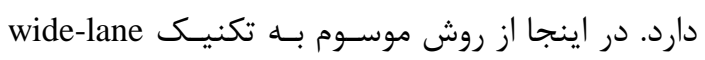

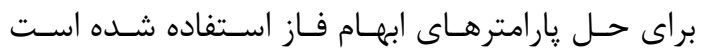

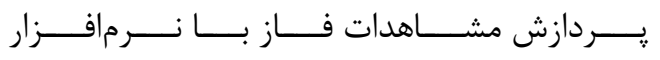
خاه GAMIT/GLOBK خلاصه كرد: در مرحلــه اول (يــردازش روزانــه) بــا اسـتفاده از 


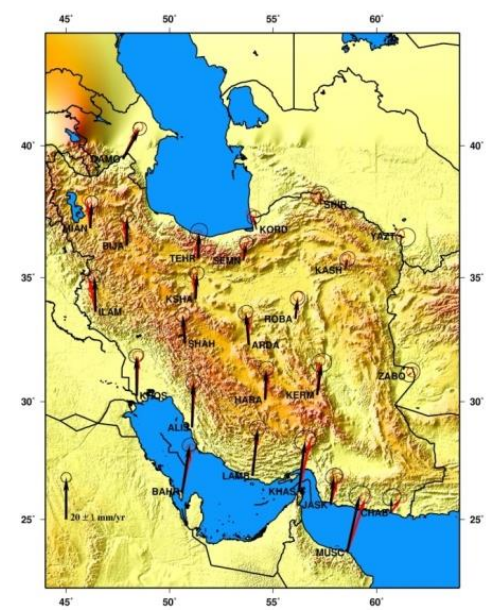

شكل س. ميدان سرعت ايستخًاه GPS شبكه ايران سراسرى

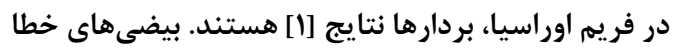
در سطح اطمينان هو دروار أجد ترسيم شدهاند.

بررســى ميــدانهــاى ســرعت محاســبه شــده در

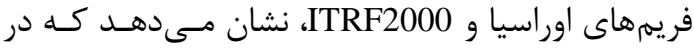

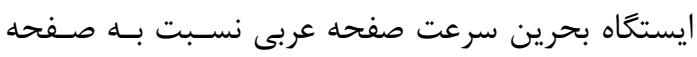

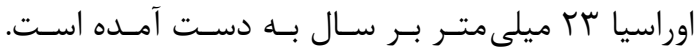
ايستخاههاى YAZT و ZABO نسبت به صفحه اوراسـيا

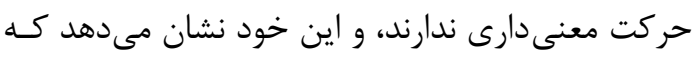

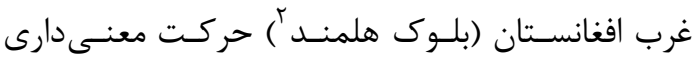
نسبت به صفحه اوراسـيا نـدارد. ايسـتخاههـاى MIAN،

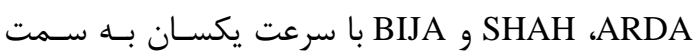

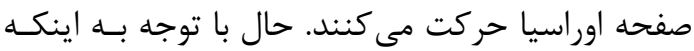

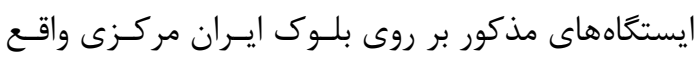

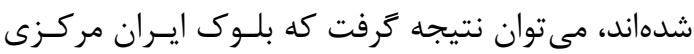

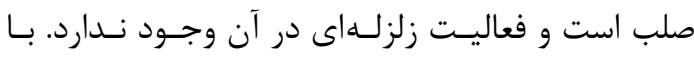

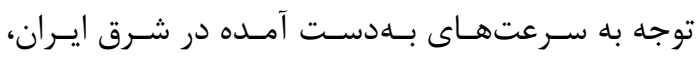

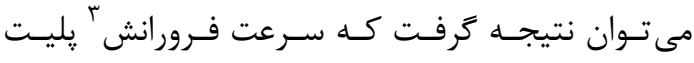
اقيانوسى عربى نسبت به ناحيه مكران، (سرعت ايستخاه

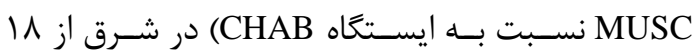
ميلى متر بر سال تا غرب ها ه ميلى متر بـر سـال كاســـه

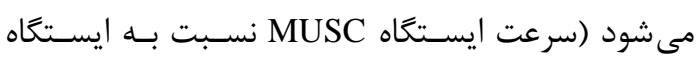

.[1] (JASK

1. Cycle slip

2. Helmand block

3. Subduction
صحت و درستى حل ابهام در فـاز بـا مقايسـهـ بـين

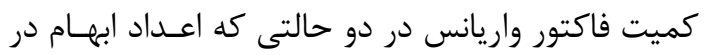
فاز اعشارى هستند (bias-free) و حالتى كه اعداد ابهام در فاز صـحيحانــ (bias-fixed)، ارزيـابى مسى شــود. در صورت حل صحيح ابهام فاز، كميت فاكتور واريانس بايد تغييرات بس ناجيزى داشته باشد [9].

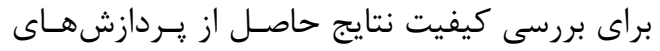
روزانه، كميت ريشه فاكتور واريـانس و تصـحيحات وارد برد شده به مختصات ايستخاه مورد ارزيابى قـرار مـى خيـرد.

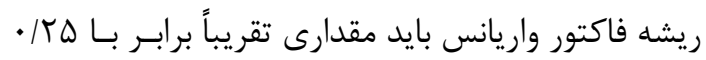

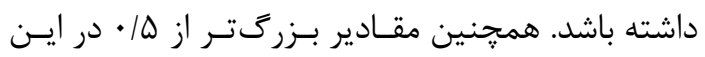

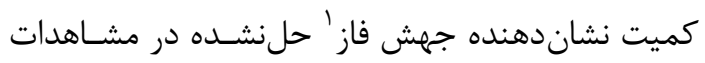
فاز موج حامل است. علاوه بر اين، مقـدار تصـحيح وارد

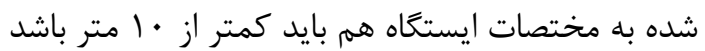

در يردازش نهايى (اسـتفاده از نــرمافـزار GLOBK) آن دسته از نتايج روزانهاى به كار رفتهاند كه ابهـام فـاز

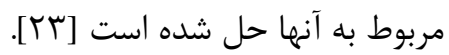

\section{F}

ميدان سرعت محاسبه شده از دادههاى سـال 1999 تـا ه • · م در فريم اوراسيا محاسبه گرديـده و در جـدول 1

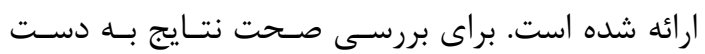

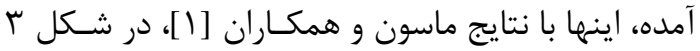

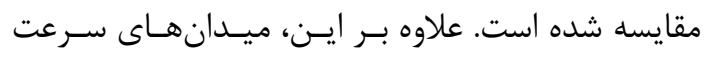

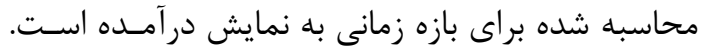

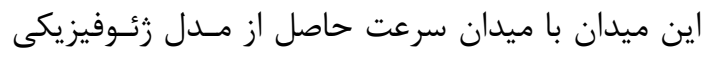

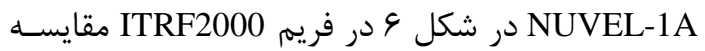

شده است [YT [T

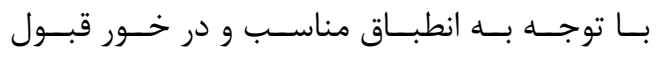
ميدانهاى سرعت محاسبه شده در اين مقاله، و ميـدان سرعتى كه ماسون و همكـاران [1] از دادههـايى مشـابه

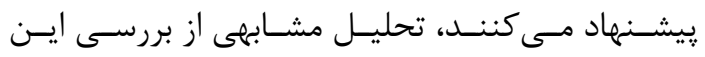

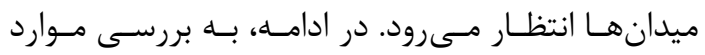
مختلف قابل استنتاج از مطالعه اين ميدانهــا يرداختـهـ مئه

$$
\text { مىشود. }
$$


سرعت مشاهده شده در ايستخاههاى GPS، از جنوب به

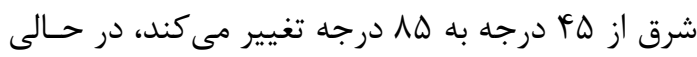

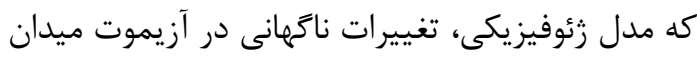

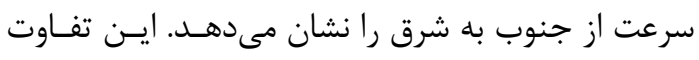

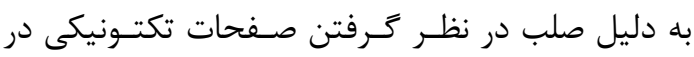
تعريف مدل زئوفيزيكى است. بـه عـلاوه، در ايسن مـدل

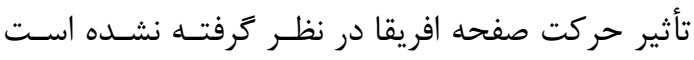

در مقايسه ميدان سرعت بهدست آمده از مشاهدات GPS

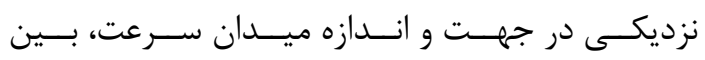
ايستخاه هايى كه بر روى صفحه عربستان قرار زرفتهانـد بـ (MUSC, KHAS, BAHR, KHOS, ILAM) شرقى ترين ايستخاههاى شبكه (ZABO، YAZT) كه بر روى صفحه اوراسيا قرار گرفتهاند، مشاهده مى شىود. بين

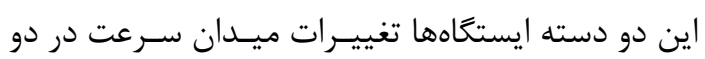
نخرش متفاوت است. به عبارت ديخــر، آزيمـوت ميـدان

جدول 1. ميدان سرعت ايستخاههاى ايران در فريم EURASI، خطاى هر يك از مؤلفههاى ميدان سرعت در سطح اطمينان

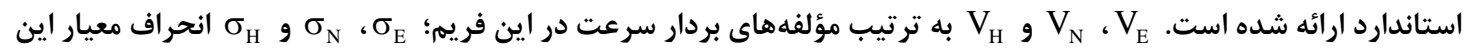

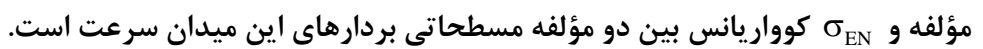

\begin{tabular}{|c|c|c|c|c|c|c|c|c|c|}
\hline St. & Lon. $\left(^{\circ}\right)$ & Lat. $\left(^{\circ}\right)$ & $\begin{array}{c}\mathrm{V}_{\mathrm{E}} \\
(\mathrm{mm} / \mathrm{y})\end{array}$ & $\begin{array}{c}\sigma_{\mathrm{E}} \\
(\mathrm{mm} / \mathrm{y})\end{array}$ & $\begin{array}{c}\mathrm{V}_{\mathrm{N}} \\
(\mathrm{mm} / \mathrm{y})\end{array}$ & $\begin{array}{c}\sigma_{\mathrm{N}} \\
(\mathrm{mm} / \mathrm{y})\end{array}$ & $\begin{array}{c}\sigma_{\mathrm{EN}} \\
(\mathrm{mm} / \mathrm{y})\end{array}$ & $\begin{array}{c}\mathrm{V}_{\mathrm{H}} \\
(\mathrm{mm} / \mathrm{y})\end{array}$ & $\begin{array}{c}\sigma_{\mathrm{H}} \\
(\mathrm{mm} / \mathrm{y})\end{array}$ \\
\hline ALIS & 51.082 & 28.919 & 0.27 & 1.54 & 21.9 & 1.45 & 0.055 & -1.45 & 2.41 \\
\hline ARDA & 53.822 & 32.313 & -1.83 & 1.51 & 15.69 & 1.43 & 0.053 & 18.82 & 2.33 \\
\hline ARTU & 58.560 & 56.430 & 2.49 & 0.23 & -1.74 & 0.23 & 0.016 & -2.52 & 1.99 \\
\hline BAHR & 50.608 & 26.209 & 4.42 & 1.56 & 23.23 & 1.65 & -0.019 & 1.48 & 1.38 \\
\hline BIJA & 47.930 & 36.232 & -0.26 & 1.38 & 14.06 & 1.32 & 0.031 & -3.11 & 2.30 \\
\hline CHAB & 60.694 & 25.300 & 0.00 & 1.89 & 7.75 & 1.70 & 0.073 & 0.82 & 2.82 \\
\hline DAMO & 47.744 & 39.513 & 7.73 & 1.38 & 14.28 & 1.3 & 0.045 & 8.77 & 2.21 \\
\hline HARA & 54.608 & 30.079 & 0.18 & 1.56 & 14.92 & 1.47 & 0.062 & 13.22 & 2.62 \\
\hline ILAM & 46.427 & 33.648 & -0.70 & 1.42 & 17.03 & 1.32 & 0.035 & -1.82 & 2.27 \\
\hline JASK & 57.767 & 25.636 & 1.34 & 1.75 & 13.95 & 1.61 & 0.069 & -2.80 & 2.85 \\
\hline KASH & 58.464 & 35.293 & 0.88 & 1.58 & 5.38 & 1.49 & 0.055 & -1.05 & 2.40 \\
\hline KERM & 57.119 & 30.277 & 1.94 & 2.02 & 15.49 & 1.87 & 0.05 & 6.06 & 2.97 \\
\hline KHAS & 56.233 & 26.208 & 2.92 & 2.16 & 24.57 & 1.95 & 0.06 & -35.24 & 3.32 \\
\hline KHOS & 48.409 & 30.246 & -0.49 & 1.51 & 19.20 & 1.41 & 0.05 & 6.20 & 2.42 \\
\hline KORD & 54.199 & 36.860 & -1.64 & 1.38 & 5.73 & 1.35 & 0.047 & -66.29 & 2.43 \\
\hline KSHA & 51.255 & 34.150 & 0.32 & 1.45 & 12.37 & 1.38 & 0.047 & -2.35 & 2.3 \\
\hline LAMB & 54.004 & 26.883 & 2.11 & 1.69 & 23.13 & 1.55 & 0.054 & 0.14 & 3.26 \\
\hline MIAN & 46.162 & 36.908 & 0.43 & 1.34 & 12.43 & 1.28 & 0.024 & 25.75 & 2.18 \\
\hline MUSC & 58.569 & 23.564 & 5.97 & 2.12 & 27.18 & 1.99 & 0.059 & 31.16 & 2.81 \\
\hline ROBA & 56.070 & 33.369 & -2.03 & 1.77 & 9.62 & 1.70 & 0.031 & 16.06 & 2.31 \\
\hline SEMN & 53.564 & 35.662 & 1.15 & 1.40 & 8.26 & 1.35 & 0.048 & -0.39 & 2.42 \\
\hline SHAH & 50.748 & 32.367 & -1.50 & 1.47 & 13.91 & 1.39 & 0.048 & -4.54 & 2.34 \\
\hline SHIR & 57.308 & 37.814 & -0.87 & 1.86 & 4.72 & 1.77 & 0.033 & 11.33 & 2.62 \\
\hline TEHR & 51.386 & 35.747 & -0.09 & 1.76 & 12.78 & 1.70 & 0.032 & -6.93 & 2.32 \\
\hline YAZT & 61.034 & 36.601 & 3.35 & 1.92 & -0.29 & 1.84 & 0.039 & -1.27 & 2.81 \\
\hline $\mathrm{ZABO}$ & 61.517 & 31.049 & 0.87 & 1.95 & 2.06 & 1.89 & 0.052 & -2.09 & 2.59 \\
\hline
\end{tabular}




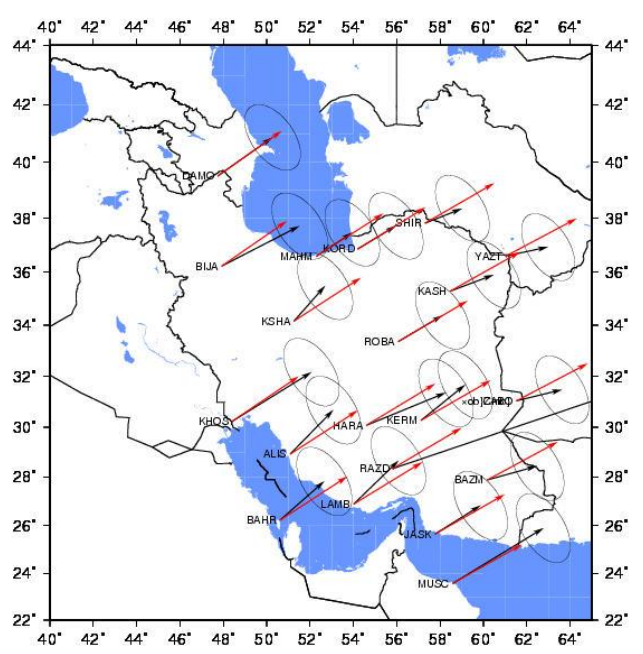

شكل 9. مقايسه ميدان سرعت حاصل از يردازش مشاهدات

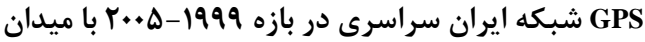
سرعت حاصل از مدل زئوفيزيكى NUVEL-1A قرمزرنغ) در فريم ITRF2000 بيضى هاى خطا در سطح اطمينان هو درصد ترسيم شدهاند.

ه- آناليز تحليلى تغيير شكل ارتفاعى در سـطح فلات ايران آحاهى از روند تغيير شكل ارتفاعى در ايران مىتواند بـهـ

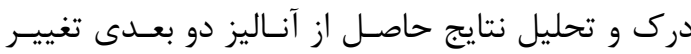
شكل در كشور كمك كند. علاوه بر اين، همان گونه كــهـ در مقدمه اين مقاله اشاره شد، دستيابى به الگوى تغيير شكل ارتفاعى مناسب و يذيرفتنى براى كشور نخسـتين

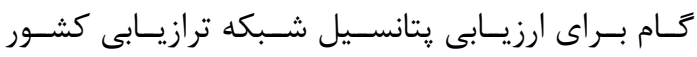

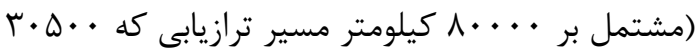
كيلومتر آن ترازيابى درجه يك است) براى آشكارسازى روند تغيير شكلهاى يوسـته زمسـين بـه عنــوان يكـى از

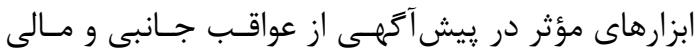

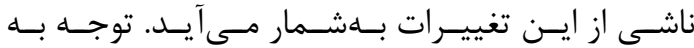
واقعيتهايى جون مدت زمان طولانى لازم بــراى انجـام يا تكرار مشاهدات شبكه ترازيابى دقيـق سراسـرى (دور

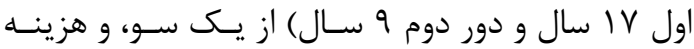

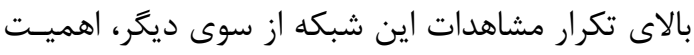

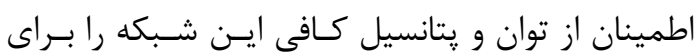

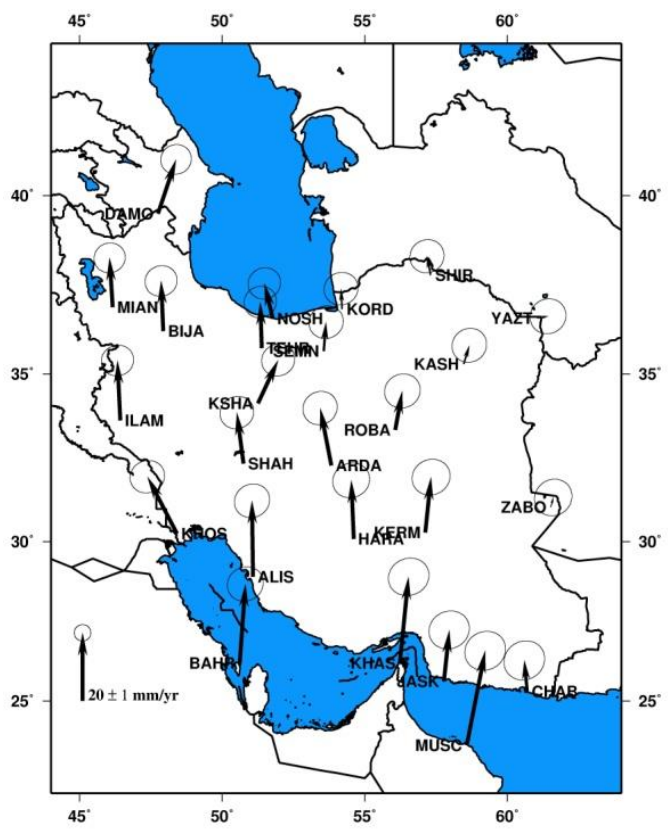

شكل F. ميدان سرعت شبكه ايران بين سالهاى

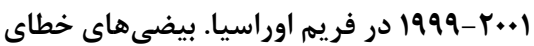

موقعيت نقاط در سطح اطمينان هو درصد

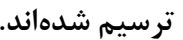

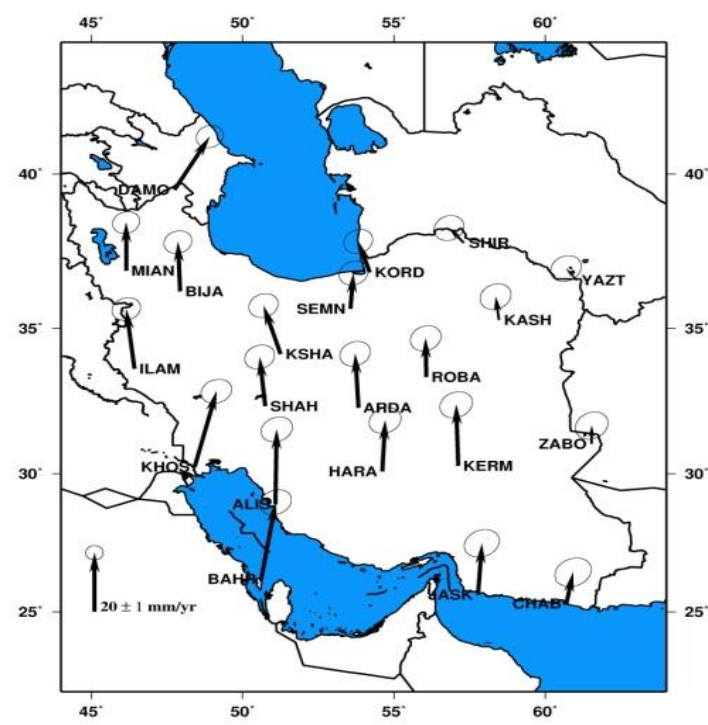

شكل ه. ميدان سرعت شبكه ايران بين سالهاى

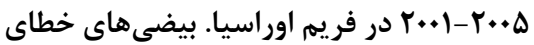

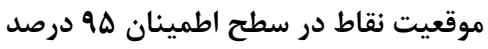

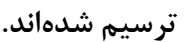


$\mathrm{H}=\frac{1}{2} \mathrm{~L}_{\alpha \beta} \mathrm{f}^{\alpha \beta}, \alpha, \beta \in\{1,2\}$

رابطه (IT)

همجنين مى توان نشان داد كه تغييرات ايـن معيـار

انحنا از رابطه (T I) محاسبه مىشود [1 II)].

رابطه (IT)

$\delta \mathrm{H}=\left(\overline{\mathrm{f}}_{\alpha \beta} \overline{\mathrm{L}}_{\alpha \beta}-\mathrm{f}_{\alpha \beta} \mathrm{L}_{\alpha \beta}\right) / 2=\mathrm{f}_{\alpha \beta} \delta \mathrm{L}_{\alpha \beta}+\overline{\mathrm{L}}_{\alpha \beta} \delta \mathrm{f}_{\alpha \beta}$

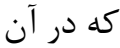

(If) (1) (1) (بطه

$\delta f_{\alpha \beta}=\bar{f}_{\alpha \beta}-f_{\alpha \beta}=x_{i, \alpha} z_{i, \beta}+x_{i, \beta} z_{i, \alpha}+\ldots=\varepsilon_{\alpha \beta}$

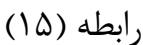

$\delta \mathrm{L}_{\alpha \beta}=\overline{\mathrm{L}}_{\alpha \beta}-\mathrm{L}_{\alpha \beta}=$

$\varepsilon_{\mathrm{ijk}}\left[\mathrm{x}_{\mathrm{j}, 1} \mathrm{x}_{\mathrm{k}, 2} \mathrm{z}_{\mathrm{i}, \alpha \beta}+\left(\mathrm{x}_{\mathrm{j}, 1} \mathrm{z}_{\mathrm{k}, 2}+\mathrm{x}_{\mathrm{k}, 2} \mathrm{z}_{\mathrm{j}, 1}\right)\right] / \mathrm{f}^{1 / 2}$

$+\mathrm{L}_{\alpha \beta} \delta \mathrm{f} / 2 \mathrm{f}$

در رابطه (IF)

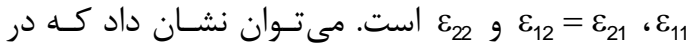

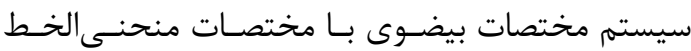
$\mathrm{u}^{\alpha}=(\lambda, \phi), \alpha \in\{1,2\}$

$\mathrm{f}_{\alpha \beta}=\left[\left(\mathrm{R}_{1}+\mathrm{H}\right)^{2} \cos ^{2} \phi+\left(\mathrm{H}_{, 1}\right)^{2}\right] \delta_{\alpha}^{1} \delta_{\beta}^{1}$

$$
+\left(\delta_{\alpha}^{1} \delta_{\beta}^{2}+\delta_{\alpha}^{2} \delta_{\beta}^{1}\right) \mathrm{H}_{, 1} \mathrm{H}_{, 2}+
$$

رابطه (19)

$\left[\left(\mathrm{R}_{1}+\mathrm{H}\right)^{2}+\left(\mathrm{H}_{, 2}\right)^{2}\right] \delta_{\alpha}^{2} \delta_{\beta}^{2}$ $\mathrm{x}_{\mathrm{i}, 1} \mathrm{z}_{\mathrm{i}, 1}=\left[\mathrm{z}_{, 1}^{1}+\left(\Gamma_{1 \mathrm{a}}^{1}+\Gamma_{3 \mathrm{a}}^{1} \mathrm{H}_{, 1}\right) \mathrm{z}^{\mathrm{a}}\right] \mathrm{g}_{11}+(\mathrm{V})$ (ابط )
$\left[\mathrm{z}_{, 1}^{3}+\left(\Gamma_{1 \mathrm{a}}^{3}+\Gamma_{3 \mathrm{a}}^{3} \mathrm{H}_{, 1}\right) \mathrm{z}^{\mathrm{a}}\right] \mathrm{H}_{, 1}$

$\mathrm{x}_{\mathrm{i}, \mathrm{1}} \mathrm{z}_{\mathrm{i}, 2}=\left[\mathrm{z}_{, 2}^{1}+\left(\Gamma_{2 \mathrm{a}}^{1}+\Gamma_{3 \mathrm{a}}^{1} \mathrm{H}_{, 2}\right) \mathrm{z}^{\mathrm{a}}\right] \mathrm{g}_{11}+$

$\left[\mathrm{z}_{, 2}^{3}+\left(\Gamma_{2 \mathrm{a}}^{3}+\Gamma_{3 \mathrm{a}}^{3} \mathrm{H}_{, 1}\right) \mathrm{z}^{\mathrm{a}}\right] \mathrm{H}_{, 2}$

رابطه (1)

$\mathrm{x}_{\mathrm{i}, 2} \mathrm{z}_{\mathrm{i}, 1}=\left[\mathrm{z}_{, 1}^{2}+\left(\Gamma_{1 \mathrm{a}}^{2}+\Gamma_{3 \mathrm{a}}^{2} \mathrm{H}_{, 1}\right) \mathrm{z}^{\mathrm{a}}\right] \mathrm{g}_{22}+$
$\left[\mathrm{z}_{, 1}^{3}+\left(\Gamma_{1 \mathrm{a}}^{3}+\Gamma_{3 \mathrm{a}}^{3} \mathrm{H}_{, 1}\right) \mathrm{z}^{\mathrm{a}}\right] \mathrm{H}_{, 2}$

1. Permutation Tensor

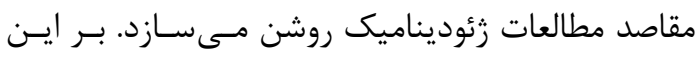
اساس، مطالعه تغيير شكل هاى ارتفاعى يوسته زمين در

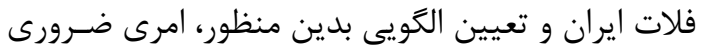
و اجتنابنايذير تلقى مىشود. در تئورى تحليلى آناليز تغيير شـكل، تغييـر شـكل سطحى يوسته زمين از طريق مطالعه تغييرات فرمهـاى اساسى اول و دوم گوس صورت مى يذيرد [1 [1]. جنانجه

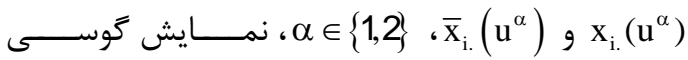
موقعيـت نقـاط P از رويـه F در لحظـات t و سيستم مختصات S و S باشند، واضح است كه جنانجه $: \mathrm{S} \equiv \overline{\mathrm{S}}$

$\mathrm{z}_{\mathrm{i} .}\left(\mathrm{u}^{\alpha}\right)=\overline{\mathrm{x}}_{\mathrm{i} .}\left(\mathrm{u}^{\alpha}\right)-\mathrm{x}_{\mathrm{i} .}\left(\mathrm{u}^{\alpha}\right) \quad$ (ابطه

جابهجايى نقاط P است. در اين رابطه uم مختصات منحنى الخط نقاط P در سيستم مختصات منحنى الخـط اختيارى است. در اين صورت، دو فرم اساسى اول و دوم كوس به ترتيب عبارتاند از [11]:

$\mathrm{f}_{\alpha \beta}=\mathrm{x}_{\mathrm{i}, \alpha} \mathrm{x}_{\mathrm{i}, \beta}, \overline{\mathrm{f}}_{\alpha \beta}=\overline{\mathrm{x}}_{\mathrm{i}, \alpha} \overline{\mathrm{x}}_{\mathrm{i}, \beta}$

رابطه (·)

$\mathrm{L}_{\alpha \beta}=\varepsilon_{\mathrm{ijk}} \mathrm{x}_{\mathrm{j}, 1} \mathrm{x}_{\mathrm{k}, 2} \mathrm{f}^{-1 / 2}, \overline{\mathrm{L}}_{\alpha \beta}=\varepsilon_{\mathrm{ijk}} \overline{\mathrm{x}}_{\mathrm{j}, 1} \overline{\mathrm{x}}_{\mathrm{k}, 2} \overline{\mathrm{f}}^{-1 / 2}$

$f_{\alpha \beta} ، x_{i, \alpha}=\partial x_{i} / \partial u^{\alpha}$ در اين روابط به عنوان مثال

و $\bar{f}_{\alpha \beta}$ مختصات S و $\mathrm{S}$

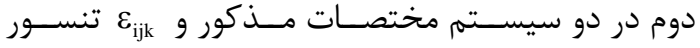
يرموتيشن ' است كه به صورت زير تعريف مىشود:

رابطه (11)

$\varepsilon_{\mathrm{ijk}}=\varepsilon^{\mathrm{ijk}}=\left\{\begin{array}{lll}+1 & \text { if } \mathrm{i}, \mathrm{j}, \mathrm{k} \text { are cyclic } \\ -1 & \text { if } \mathrm{i}, \mathrm{j}, \mathrm{k} \text { are anticyclic } \\ 0 & \text { if } \mathrm{i}, \mathrm{j}, \mathrm{k} \text { are acyclic }\end{array}\right.$

با استفاده از دو فـرم اساسـى اول و دوم خــوس بــهـ

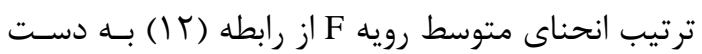

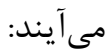


علاوه بر اين، در صورتى كسه دادهــاى ورودى داراى

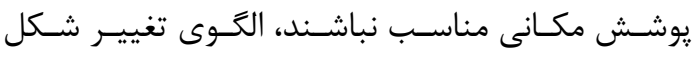

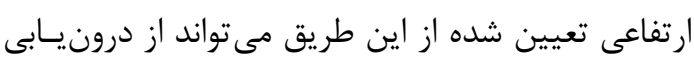
ميدانهاى سرعت و ارتفاع نقاط شبكه تأثير بيذيرد.

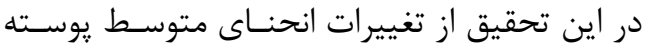
زمين به عنوان معيـارى بـــاى تشـخيص الخَـوى تغييـر شكل ارتفاعى سطحى يوسته در فـلات ايــان اسـتفاده

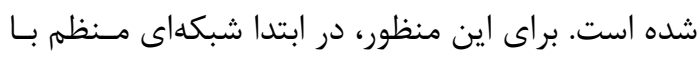

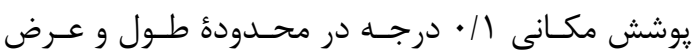
جغرافيايى ايران توليد شد. سيس ارتفاع نقـاط شـبكه و

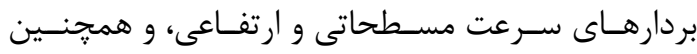

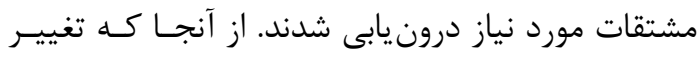

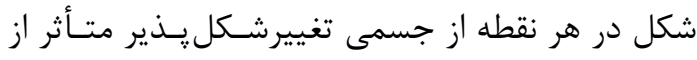

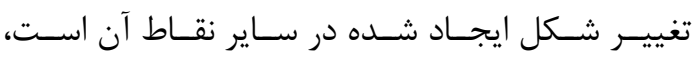

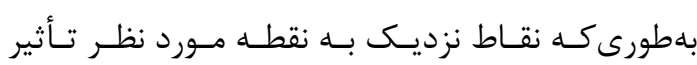

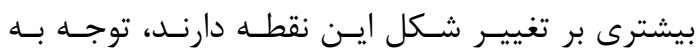

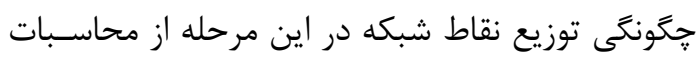

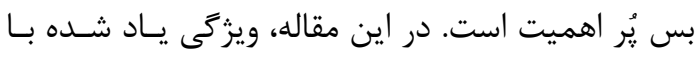
استفاده از كرنلى كه تابعى نمايى از فاصله نقاط مختلف دانف

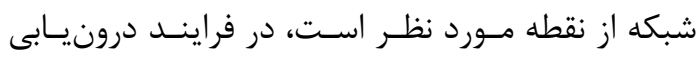

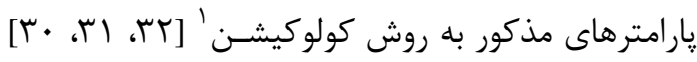

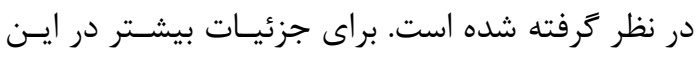

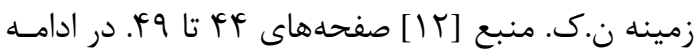
تغيير انحناى سطحى يوسته زمين محاسبه شد و از اين

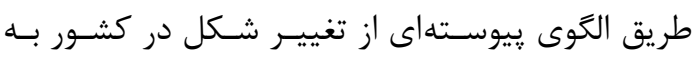
دست آمد. براى اين منظور مجموعه برنامههايى به زبان

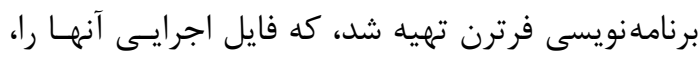

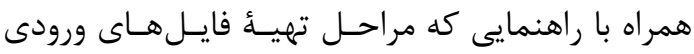
مورد نياز در مراحل مختلف محاسباتى يـاد شـده، را در

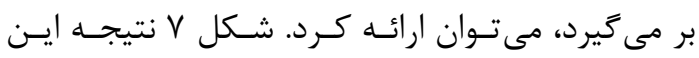

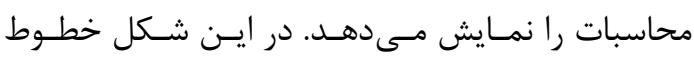

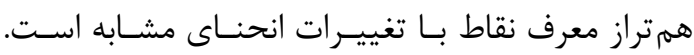

1. Collocation $\mathrm{x}_{\mathrm{i}, 2} \mathrm{Z}_{\mathrm{i}, 2}=\left[\mathrm{z}_{, 2}^{1}+\left(\Gamma_{2 \mathrm{a}}^{1}+\Gamma_{3 \mathrm{a}}^{1} \mathrm{H}_{, 2}\right) \mathrm{z}^{\mathrm{a}}\right] \mathrm{g}_{22}+(Y \cdot)$ رابطه
$\left[\mathrm{z}_{, 2}^{3}+\left(\Gamma_{2 \mathrm{a}}^{3}+\Gamma_{3 \mathrm{a}}^{3} \mathrm{H}_{, 2}\right) \mathrm{z}^{\mathrm{a}}\right] \mathrm{H}_{, 2}$

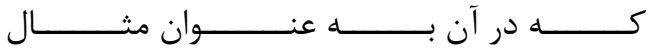

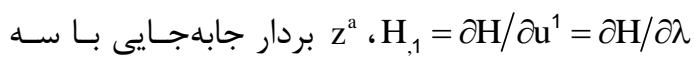

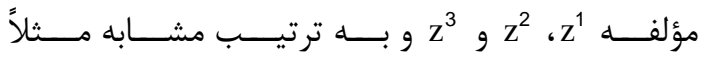

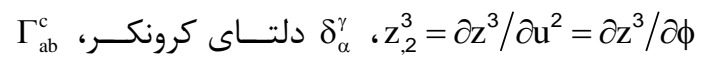
سـ . $V=\left(\begin{array}{ll}1 & 2 \\ & +e^{2}\end{array}\right)^{1 / 2} \quad$ c $=a^{2} / b \cdot R_{2}=c / V^{3}$ نصف قطر بزرگتر و a ce" ce c $^{\prime 2}=\left(a^{2}-b^{2}\right) / b^{2}$

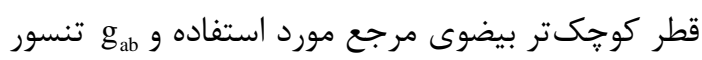

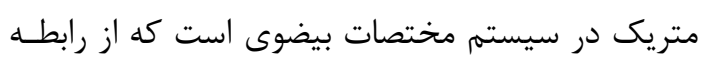

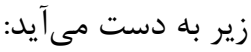

$$
\begin{aligned}
\mathrm{g}_{\mathrm{ab}}= & \left(\mathrm{R}_{1}+\mathrm{H}\right)^{2} \cos ^{2} \phi \delta_{\mathrm{a}}^{1} \delta_{\mathrm{b}}^{1}+ \\
& \left(\mathrm{R}_{2}+\mathrm{H}\right)^{2} \delta_{\mathrm{a}}^{2} \delta_{\mathrm{b}}^{2}+\delta_{\mathrm{a}}^{3} \delta_{\mathrm{b}}^{3} \\
\Gamma_{\mathrm{ab}}^{\mathrm{c}} & =\mathrm{g}^{\mathrm{cd}}\left(\mathrm{g}_{\mathrm{ad}, \mathrm{b}}+\mathrm{g}_{\mathrm{bd}, \mathrm{a}}-\mathrm{g}_{\mathrm{ab}, \mathrm{d}}\right) / 2
\end{aligned}
$$

براى مشتقات تنسور متريك نسبت بـهـ سـه مؤلفـهـ مختصاتى $\left\{\begin{array}{l}a, 23 \\ a\end{array}\right.$

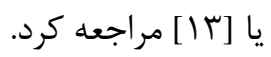
همان كَونه كه از روابط نوشته شده مئتودان ديـد، در

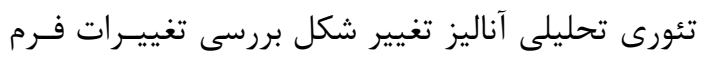

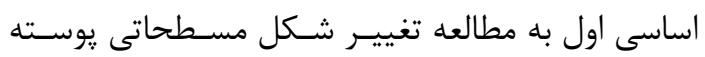
زمين و بررسى تغييرات فرم اساسى دوم از طريق يكى لئس از معيارهاى ممكن همجون تغيير انحناى متوسط سطح

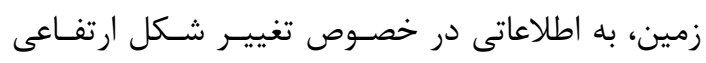
يوسته زمين منتهى مى زَردد.

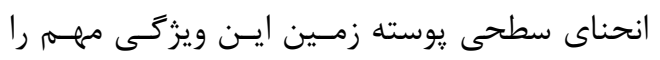

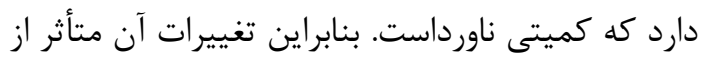
تغييـرات احتمـالى سيسـتم مختصـات مـورد اسـتفاده نخواهد بود. اين ويزَگى مزيتى عمده براى ايـن روش در

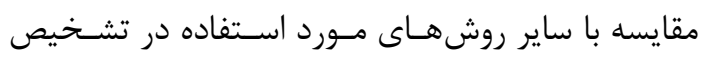

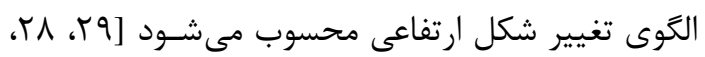
[T 


\section{سال اول • شماره نخست • ياييز ب وسأ}

كه اين زمين لرزههـا غالبـاً در حواشـى شـمال شـرقى و

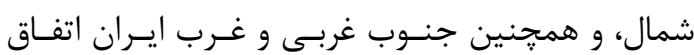

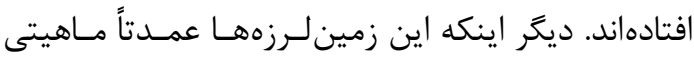

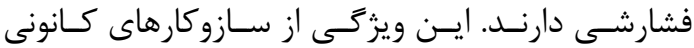

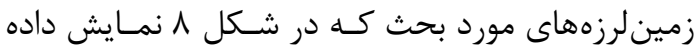

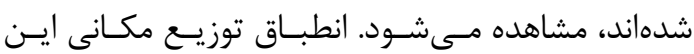
زمينلرزهها با حوزهاى تغيير انحناى منعكس در نتايج

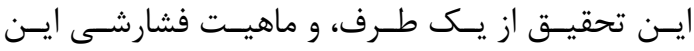

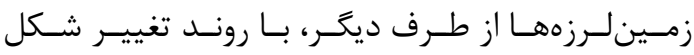
ييشنهادى در نتايج اين تحقيق سازكار است.

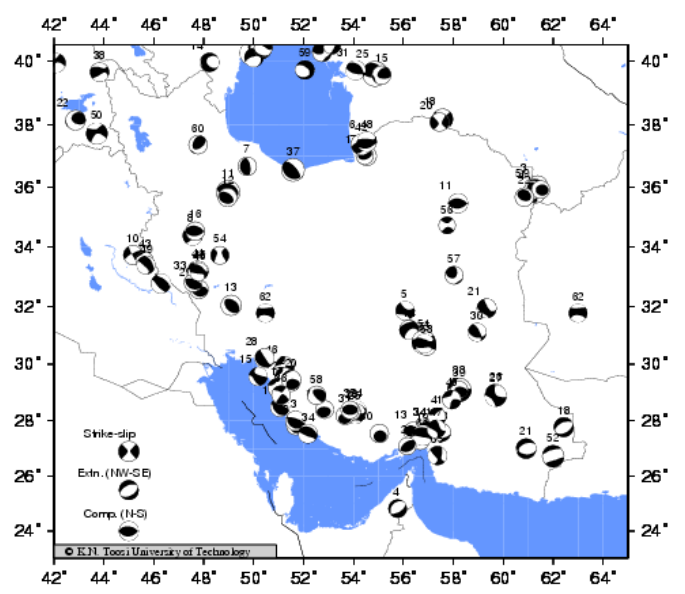

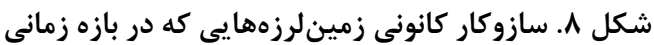

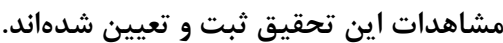

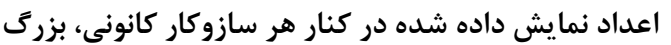
آن آن زمين لرزه است.

اين الكوى تغيير شـكل نخسـتين تصـوير جـامع از

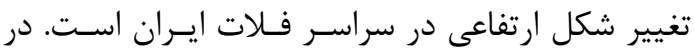

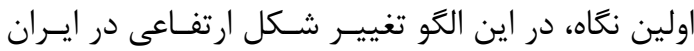

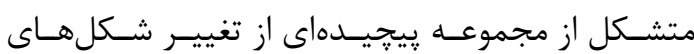
ارتفاعى محلى پيشبينى مى رَدد. با اين حال، شناخت

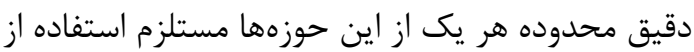
شبكداى با تراكم مناسبتر از نقاط اندازهيرى است.

1. Uplift

2. Settlement

3. Subduction Zone

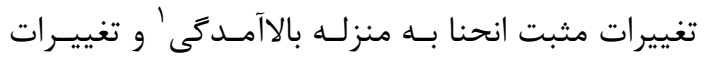
منفى آن به منزله نشست بَ در محدوده مورد نظر است.

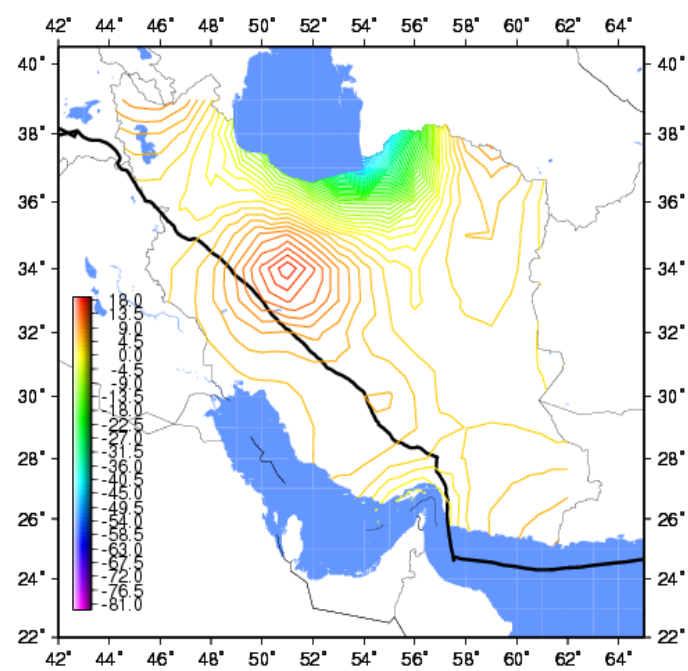

شكل V. الكوى تغيير شكل ارتفاعى در كشور حاصل از مشاهدات GPS شبكه موردى مرسوم به ايران سراسرى.

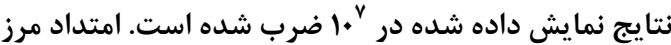

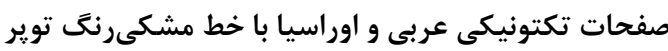

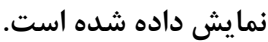

\section{9- نتيجه كَيرى}

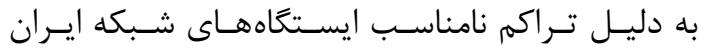

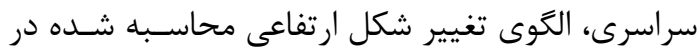

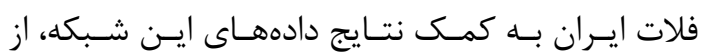

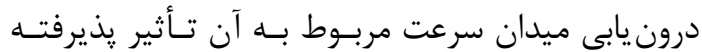
است. با اين حال جزئيات مندرج در اين نتايج، انطبـاقى ترئي

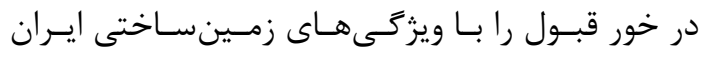

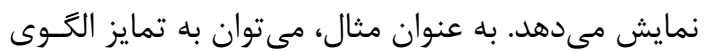
تغيير شكل ارتفـاعى در امتـداد سلسـله جبــال البــرز و و

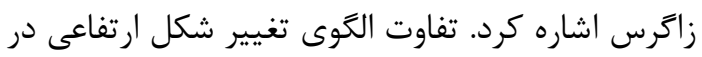

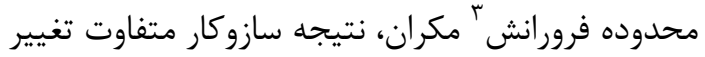

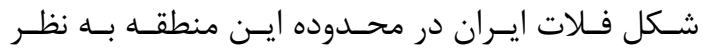

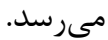
بررسى سازوكار كانونى زمينلرزهـهـيـى كـهـ در بـازه

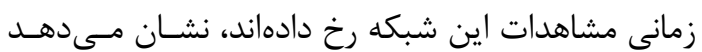




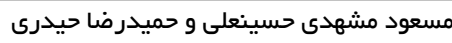

V- ضميمه

جدول ا- ض. تكراريذيرى مشاهدات سال 1999: ايستخاههاى شبكه ايران با IR و

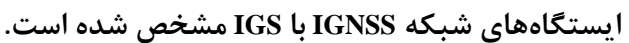

\begin{tabular}{|c|c|c|c|c|c|c|c|c|c|c|c|c|c|c|}
\hline \multicolumn{3}{|c|}{ ايستخاه } & 259 & 260 & 261 & 262 & 263 & 264 & 265 & 266 & 267 & 268 & 269 & Pillar/Tripod \\
\hline ARTU & IGS & 11 & $x$ & $x$ & $x$ & $x$ & $x$ & $x$ & $x$ & $x$ & $x$ & $x$ & $x$ & $\mathrm{P}$ \\
\hline BAHR & IGS & 11 & $x$ & $x$ & $x$ & $x$ & $x$ & $x$ & $x$ & $x$ & $x$ & $x$ & $x$ & $\mathrm{P}$ \\
\hline ZECK & IGS & 11 & $x$ & $x$ & $x$ & $x$ & $x$ & $x$ & $x$ & $x$ & $x$ & $x$ & $x$ & $\mathrm{P}$ \\
\hline AMMN & IGS & 11 & $x$ & $x$ & $x$ & $x$ & $x$ & $x$ & $x$ & $x$ & $x$ & $x$ & $x$ & $\mathrm{P}$ \\
\hline KIT3 & IGS & 8 & $x$ & $x$ & $x$ & $x$ & $x$ & $x$ & $x$ & $x$ & & & & $\mathrm{P}$ \\
\hline KHAS & IR & 11 & $x$ & $x$ & $x$ & $x$ & $x$ & $x$ & $x$ & $x$ & $x$ & $x$ & $x$ & $\mathrm{~T}$ \\
\hline MUSC & IR & 11 & $x$ & $x$ & $x$ & $x$ & $x$ & $x$ & $x$ & $x$ & $x$ & $x$ & $x$ & $\mathrm{P}$ \\
\hline NKS1 & IR & 10 & & $x$ & $x$ & $x$ & $x$ & $x$ & $x$ & $x$ & $x$ & $x$ & $x$ & $\mathrm{~T}$ \\
\hline SHIR & IR & 10 & $x$ & $x$ & $x$ & $x$ & & $x$ & $x$ & $x$ & $x$ & $x$ & $x$ & $\mathrm{P}$ \\
\hline TEHR & IR & 5 & & & & & $x$ & $x$ & $\times$ & $x$ & $x$ & & & $\mathrm{P}$ \\
\hline $\mathrm{ZABO}$ & IR & 10 & $x$ & $x$ & $x$ & $x$ & & $x$ & $x$ & $x$ & $x$ & $x$ & $x$ & $\mathrm{P}$ \\
\hline ALIS & IR & 4 & $x$ & $x$ & $x$ & $x$ & & & & & & & & $\mathrm{P}$ \\
\hline NOSH & IR & 4 & $x$ & $x$ & $x$ & $x$ & & & & & & & & $\mathrm{P}$ \\
\hline ARDA & IR & 4 & $x$ & $x$ & $x$ & $x$ & & & & & & & & $\mathrm{P}$ \\
\hline BIJA & IR & 4 & $x$ & $x$ & $x$ & $x$ & & & & & & & & $\mathrm{P}$ \\
\hline DAMO & IR & 4 & $x$ & $x$ & $x$ & $x$ & & & & & & & & $\mathrm{P}$ \\
\hline ILAM & IR & 4 & $x$ & $x$ & $x$ & $x$ & & & & & & & & $\mathrm{P}$ \\
\hline KHOS & IR & 4 & $x$ & $x$ & $x$ & $x$ & & & & & & & & $\mathrm{P}$ \\
\hline KSHA & IR & 4 & $x$ & $x$ & $x$ & $x$ & & & & & & & & $\mathrm{~T}$ \\
\hline SHAH & IR & 4 & $x$ & $x$ & $x$ & $x$ & & & & & & & & $\mathrm{~T}$ \\
\hline MIAN & IR & 4 & $x$ & $x$ & $x$ & $x$ & & & & & & & & $\mathrm{P}$ \\
\hline LAMB & IR & 4 & $x$ & $x$ & $x$ & $x$ & & & & & & & & $\mathrm{~T}$ \\
\hline YAZT & IR & 4 & & & & & & & & $x$ & $x$ & $x$ & $x$ & $\mathrm{P}$ \\
\hline BAZM & IR & 4 & & & & & & & & $x$ & $x$ & $x$ & $x$ & $\mathrm{~T}$ \\
\hline CHAB & IR & 4 & & & & & & & & $x$ & $x$ & $x$ & $x$ & $\mathrm{P}$ \\
\hline HAJI & IR & 4 & & & & & & & & $x$ & $x$ & $x$ & $x$ & $\mathrm{P}$ \\
\hline HARA & IR & 4 & & & & & & & & $x$ & $x$ & $x$ & $x$ & $\mathrm{~T}$ \\
\hline JASK & IR & 4 & & & & & & & & $x$ & $x$ & $x$ & $x$ & $\mathrm{P}$ \\
\hline KASH & IR & 4 & & & & & & & & $x$ & $x$ & $x$ & $x$ & $\mathrm{P}$ \\
\hline KERM & IR & 4 & & & & & & & & $x$ & $x$ & $x$ & $x$ & $\mathrm{~T}$ \\
\hline ROBA & IR & 4 & & & & & & & & $x$ & $x$ & $x$ & $x$ & $\mathrm{P}$ \\
\hline KORD & IR & 4 & & & & & & & & $x$ & $x$ & $x$ & $x$ & $\mathrm{P}$ \\
\hline SEMN & IR & 4 & & & & & & & & $x$ & $x$ & $x$ & $x$ & $\mathrm{P}$ \\
\hline
\end{tabular}


جدول r- ض. تكراريذيرى مشاهدات سال ا.+ץ: ايستخاههاى شبكه ايران با IR و

ايستخاههاى شبكه IGNSS با IGS مشخص شده است.

\begin{tabular}{|c|c|c|c|c|c|c|c|c|c|c|c|c|c|c|}
\hline \multicolumn{3}{|c|}{ ايستگاه } & 280 & 281 & 282 & 283 & 284 & 285 & 286 & 287 & 288 & 289 & 290 & 291 \\
\hline ARTU & IGS & 12 & $x$ & $x$ & $x$ & $x$ & $\times$ & $x$ & $x$ & $\times$ & $\times$ & $x$ & $x$ & $x$ \\
\hline AMMN & IGS & 9 & $\times$ & $\times$ & $\times$ & $\times$ & x & $\times$ & $\times$ & $\times$ & $\times$ & & & \\
\hline BAHR & IGS & 10 & $\times$ & $\times$ & $\times$ & x & $\times$ & $\times$ & $\times$ & $\times$ & $\times$ & $\times$ & & \\
\hline KIT3 & IGS & 12 & $\times$ & $\times$ & $\times$ & $\times$ & $\times$ & $\times$ & $\times$ & $x$ & $\times$ & $x$ & $\times$ & $\times$ \\
\hline ZECK & IGS & 12 & x & $\times$ & x & $\times$ & $\times$ & $\times$ & $\times$ & $\times$ & $\times$ & $x$ & $\times$ & $\times$ \\
\hline MUSC & IR & 10 & & $\times$ & x & $\times$ & $x$ & $\times$ & $\times$ & $\times$ & $\times$ & $x$ & $\times$ & \\
\hline TEHN & IR & 11 & & $\times$ & $\times$ & $\times$ & $\times$ & $\times$ & $\times$ & $\times$ & $\times$ & $\times$ & $\times$ & $\times$ \\
\hline ZABO & IR & 11 & & $\times$ & $\times$ & $\times$ & $\times$ & x & $\times$ & $\times$ & $\times$ & $\times$ & $\times$ & $\times$ \\
\hline KASH & IR & 12 & x & x & x & $\times$ & $x$ & $\times$ & $\times$ & $\times$ & $\times$ & x & $\times$ & $\times$ \\
\hline AHVA & IR & 11 & & $\times$ & $x$ & $\times$ & $\times$ & $\times$ & $\times$ & $\times$ & $\times$ & $x$ & $\times$ & $\times$ \\
\hline ALIS & IR & 12 & $\times$ & $\times$ & $\times$ & $\times$ & $\times$ & $\times$ & $\times$ & $\times$ & $\times$ & $\times$ & $\times$ & $\times$ \\
\hline ARDA & IR & 12 & $\times$ & $\times$ & $\times$ & $\times$ & $\times$ & $\times$ & $\times$ & $\times$ & $\times$ & $\times$ & $\times$ & $\times$ \\
\hline TEHR & IR & 4 & & x & $x$ & $x$ & $x$ & & & & & & & \\
\hline KSHA & IR & 4 & & $\times$ & $\times$ & $\times$ & $\times$ & & & & & & & \\
\hline LAMB & IR & 4 & & $\times$ & $\times$ & $\times$ & $\times$ & & & & & & & \\
\hline MIAN & IR & 4 & & $\times$ & $\times$ & $x$ & $\times$ & & & & & & & \\
\hline NOSH & IR & 4 & & $x$ & $x$ & $x$ & $x$ & & & & & & & \\
\hline SHAH & IR & 4 & & $\times$ & $x$ & $x$ & $\times$ & & & & & & & \\
\hline BIIJA & IR & 4 & & $x$ & $x$ & $x$ & $x$ & & & & & & & \\
\hline ILAM & IR & 4 & & $\times$ & x & $x$ & $\times$ & & & & & & & \\
\hline DAMO & IR & 4 & & $\times$ & $\times$ & $x$ & $\times$ & & & & & & & \\
\hline KHOS & IR & 4 & & $x$ & x & $\times$ & $x$ & & & & & & & \\
\hline BAZM & IR & 3 & & & & & & & & & $\times$ & $x$ & $\times$ & \\
\hline HARA & IR & 4 & & & & & & & & & $\times$ & $\times$ & $\times$ & $\times$ \\
\hline JASK & IR & 4 & & & & & & & & & $\times$ & $\times$ & $\times$ & x \\
\hline KERM & IR & 2 & & & & & & & & & $x$ & $\times$ & & \\
\hline KHAS & IR & 4 & & & & & & & & & & $x$ & $\times$ & $x$ \\
\hline KORD & IR & 4 & & & & & & & & & $\times$ & $x$ & $\times$ & $\times$ \\
\hline ROBA & IR & 4 & & & & & & & & & $\times$ & $x$ & $\times$ & $\times$ \\
\hline SEMN & IR & 4 & & & & & & & & & $\times$ & $\times$ & $x$ & $\times$ \\
\hline SHIR & IR & 4 & & & & & & & & & $\times$ & $\times$ & $\times$ & $\times$ \\
\hline YAZT & IR & 4 & & & & & & & & & $\times$ & $\times$ & $\times$ & $\times$ \\
\hline HAJI & IR & 2 & & & & & & & & & & & $x$ & $\times$ \\
\hline
\end{tabular}


تعيين الكَوى تغيير شكل ارتفاعى سطح يوسته ...

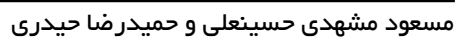

جدول س- ض. تكراريذيرى مشاهدات سال ه+.r: ايستخاههاى شبكه ايران با IR و

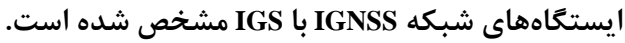

\begin{tabular}{|c|c|c|c|c|c|c|c|c|c|c|c|c|c|c|c|}
\hline \multicolumn{3}{|c|}{ ايستًاه } & 261 & 262 & 263 & 264 & 265 & 266 & 267 & 268 & 269 & 270 & 271 & 272 & 273 \\
\hline ARTU & IGS & 13 & $x$ & $x$ & $\times$ & $x$ & $x$ & $x$ & $\times$ & $x$ & $x$ & $x$ & $x$ & $\times$ & $x$ \\
\hline DRAG & IGS & 13 & $x$ & $x$ & x & $x$ & $\times$ & $x$ & $x$ & $x$ & $x$ & x & $x$ & x & $x$ \\
\hline BAHR & IGS & 13 & $x$ & $x$ & $x$ & $\times$ & $x$ & $x$ & $x$ & $x$ & $x$ & $\times$ & $x$ & $x$ & $x$ \\
\hline KIT3 & IGS & 13 & $\times$ & $x$ & $\times$ & $x$ & $x$ & $\times$ & $x$ & $x$ & $x$ & $\times$ & $\times$ & $x$ & $\times$ \\
\hline ZECK & IGS & 13 & $x$ & $x$ & $\times$ & $x$ & $\times$ & $x$ & $x$ & $x$ & $x$ & $x$ & $x$ & $x$ & $x$ \\
\hline KERM & IR & 4 & $\times$ & $\times$ & x & $\times$ & & & & & & & & & \\
\hline ZABO & IR & 5 & $x$ & x & $\times$ & $x$ & $\times$ & & & & & & & & \\
\hline HAJT & IR & 5 & & & & & $x$ & $x$ & $x$ & $x$ & $x$ & & & & \\
\hline ROBA & IR & 5 & & & & & $\times$ & $\times$ & $\times$ & $\times$ & $\times$ & & & & \\
\hline SARB & IR & 4 & & & & & & & & & $\times$ & $x$ & $\times$ & $\times$ & \\
\hline ARDA & IR & 4 & & & & & & & & & x & x & $x$ & x & \\
\hline BAZM & IR & 3 & & $x$ & $\times$ & x & & & & & & & & & \\
\hline KASH & IR & 3 & & x & $\times$ & $\times$ & & & & & & & & & \\
\hline ESFA & IR & 3 & & $\times$ & $\times$ & $\times$ & & & & & & & & & \\
\hline ILAM & IR & 3 & & $\times$ & $\times$ & $\times$ & & & & & & & & & \\
\hline MIAN & IR & 3 & & $\times$ & $\times$ & $\times$ & & & & & & & & & \\
\hline KORD & IR & 3 & & $\times$ & $\times$ & $\times$ & & & & & & & & & \\
\hline LAMB & IR & 3 & & $x$ & $x$ & $\times$ & & & & & & & & & \\
\hline SEMN & IR & 3 & & $\times$ & $\times$ & $\times$ & & & & & & & & & \\
\hline СНAB & IR & 3 & & & & & & $\times$ & $x$ & $\times$ & & & & & \\
\hline DAMO & IR & 3 & & & & & & $\times$ & $x$ & $x$ & & & & & \\
\hline KSHA & IR & 3 & & & & & & $\times$ & $x$ & $\times$ & & & & & \\
\hline KHOS & IR & 3 & & & & & & $\times$ & $x$ & $\times$ & & & & & \\
\hline RAZD & IR & 3 & & & & & & $x$ & $x$ & $\times$ & & & & & \\
\hline SHIR & IR & 3 & & & & & & $\times$ & x & $\times$ & & & & & \\
\hline SHKH & IR & 3 & & & & & & x & $\times$ & $\times$ & & & & & \\
\hline ZVNG & IR & 3 & & & & & & $x$ & $x$ & $x$ & & & & & \\
\hline ALIS & IR & 3 & & & & & & & & & & x & $x$ & $x$ & \\
\hline HARA & IR & 3 & & & & & & & & & & $\times$ & $\times$ & $\times$ & \\
\hline JASK & IR & 3 & & & & & & & & & & $\times$ & $\times$ & $\times$ & \\
\hline KHSF & IR & 3 & & & & & & & & & & $\times$ & $\times$ & $\times$ & \\
\hline SHAH & IR & 3 & & & & & & & & & & $\times$ & $x$ & x & \\
\hline YAZT & IR & 3 & & & & & & & & & & $\times$ & $\times$ & $\times$ & \\
\hline
\end{tabular}




$$
\text { - - V }
$$

[1] Masson F., J. C. D. Hatzfeld, J. Martinod, P. Vernant, F. Tavakoli and M. GhaforyAshtiani, 2005. Seismic Versus Aseismic Deformation in Iran Inferred from Earthquakes and Geodetic Data. Geophys J. Int. 160, 217-226.

[2] Lichtenegger, H. and H. Sünkel, 1989. Mathematische-Geophysikalische Model, in Österreichische Beträge zum WegenerMedals-Projekt. Mitteilungen der Geodätischen Institute der Technischen Universität Graz, 65, 61-80.

[3] Jackson, J., and D., McKenzie, 1988. The Relationship between Plate Motions and Seismic Moment Tensors, and the Rates of Active Deformation in Mediterranean and Middle East. Geophys J. Int., 93(1),45-73, doi: 10.1111/j.1365-246X.1988.tb01387.x

[4] Frank, F.C., 1966. Deduction of Earth Strains from Survey Data. Bull, Seismol. Soc. Am., 56, 35-42.

[5] Welsch, W., 1979. A Review of the Adjustment of Free Networks. Surv. Rev. 194(25), 167-180.

[6] Bibby, H.M., 1982. Unbiased Estimate of Strain from Triangulation Data Using the Method of Simultaneous Reduction. Tectonophysics, 82, 161-174.

[7] Chen, R., 1991. On the Horizontal Crustal Deformations in Finland. Helsinki, Finish Geodetic Institute.

[8] Krumm, F. and E. Grafarend, 2002. Datumfree Deformation Analysis of ITRF Networks. Artificial Satellites, 37, 75-84.

[9] Hossainali, M.M., 2006. A Comprehensive Approach to the Analysis of the $3 D$ Kinematics of Deformation. Darmstadt University of Technology, Darmstadt, Ph.D. Thesis, 150 pp.

[10] Amerian Y., 2002. Investigating Systematic Errors in Precise Digital Leveling. M.Sc. Thesis, K.N. Toosi University of Technology, Faculty of Geodesy and Geomatics Engineering, Tehran, Iran.

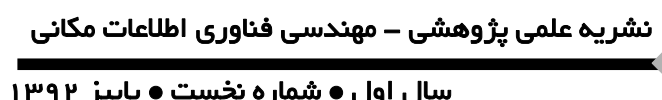

سال اول • شماره نخست • ياييز م وس

[11] Vosooghi B., 1994. An Investigation of Systematic Errors in Precise Leveling Network of Iran. M.Sc. Thesis, Department of Geodesy and Geomatics Engineering, K.N. Toosi University of Technology, Tehran, Iran.

[12] Altiner, Y., 1999. Analytical Surface Deformation Theory. Springer, ISBN: $3-540-65820-3$.

[13] Heitz, S., 1988. Coordinates in Geodesy. Springer, Berlin Heidelberg New York.

[14] Nilforoushan, F., F. Masson, P. Vernant, C. Vigny, J. Martinod, M. Abbassi, H. Nankali, D. Hatzfeld, R. Bayer, F. Tavakoli, A. Ashtiani, E. Doerflinger, M. Daignières, P. Collard, and J. Chéry, 2003. GPS Network Monitors the Arabia-Eurasia Collision Deformation in Iran. J. Geodesy, 77, 411-422.

[15] Altamimi, Z., P. Sillard and C. Boucher, 2002. ITRF 2000: A New Release of the International Terrestrial Reference Frame for Earth Science Applications. J. Geophys. Res., 107 (B10), 2214, doi: 10.1029/2001 JB 000561.

[16] Herring, T.A., R.W. King and S.C. McClusky, 2004. GPS Analysis at MIT. Gamit Reference Manual, Release 10.3, Department of Earth, Atmospheric, and Planetary Sciences Massachussetts Institute of Technology, Cambridge.

[17]Beutler G., Brockmann, E., Gurtner W., Hugentobler, U., Mervart L. and Rothacher, M., 1994. Extended Orbit Modeling Techniques at the CODE Processing Center of the International GPS Service for Geodynamics (IGS). Theory and initial results, 19, 367-386.

[18] McCarthy, D.D., 1992. IERS Standards. IERS Technical Notes, Central Bureau of IERS observatoire de Paris.

[19] Shen, C., 2004. A Method for Processing Data from a Regional Continuous Crustal Deformation GPS Monitoring Network. 
M.Sc. E. Thesis, Department of Geodesy and Geomatics Engineering, University of New Brunswick, Technical Report No. 221.

[20]Zhang, J., 1999. Investigations into the Estimation of Residual Tropospheric Delays in a GPS Network. Department of Geomatics Engineering. Alberta, Canada, Calgary, M.Sc. Thesis, $185 \mathrm{pp}$.

[21] Rothacher, M., S. Schaer et al., 1995. Determination of Antenna Phase Center Variations Using GPS Data. Paper presented at the 1995 IGS Workshop, Potsdam, Germany.

[22] Jonge, P. J., 1998. A Processing Strategy for the Application of the GPS in Networks. Publications on Geodesy in the continuation of Publications on Geodesy New Series, Published by: NCG Nederlands Commissie voor Ceodesie Netherlands Geodetic Commission, Delft, The Netherlands, Ph.D. Thesis, 250pp.

[23]Herring, T.A., R.W. King and S.C. McClusky, 2003. Global Kalman Filter VLBI and GPS Analysis Program. Globk Reference Manual, Release 10.3. Department of Earth, Atmospheric, and Planetary Sciences Massachussetts Institute of Technology, Cambridge.

[24] DeMets, C., R. G. Gordon, D. F. Argus and S. Stein, 1994. Effect of Recent Revisions to the Geomagnetic Reversal Time Scale on Estimates of Current Plate Motions. Geophys. Res. Lett., 21(20), 2191-2194, doi:10.1029/94GL02118.
[25] Vaníček, P., 1976. Vertical Crustal Movement Pattern in Maritime Canada. Canad. J. of Earth Sci., 13(5), 661-667.

[26] Lambert, A. and P. Vanicek, 1978. Contemporary Crustal Movements in Canada. Canadian Journal of Earth Sciences, 16, 647-668.

[27] Vaníček, P. and D. Nagy, 1980. Report on the Compilation of the Map of Vertical Crustal Movements in Canada. Earth Physics Branch, Open File Report No. 80-2, Ottawa.

[28] Vanicek, P., Elliott, M.R. and R. Castel $\square \square \square, \quad$ 1978. Four Dimensional Modeling Of Recent Vertical Movements in the Area of the Southern California Uplift Tectonophysics,52, 287-300.

[29] Vaníček, P., D. Christodulides, 1974. A Method for Evaluating Vertical Crustal Movements from Scattered Geodetic Relevellings. Canad. J. of Earth Sci., 11(5), 605-610.

[30] Moritz, H., 1973. Least Squares Collocation. Deucher Geodaetische Kommission, Munchen, ISBN: 3-76968162-2.

[31]Moritz, H., 1980. Advanced Physical Geodesy. Abacus Press, 500 pp., ISBN-13: 978-3879071067.

[32]Moritz H. and H. Sunkel, 1977. Approximation Methods in Geodesy: Lectures Delivered at the 2, Internat. Summer School in the Mountains on Math. Methods in Phys. Geodesy, Ramsau, Austria, August 23 - September 2, 1977, Wichmann Verlag, Karlsruhe. 


\title{
The Vertical Pattern of Surface Deformation in Iran, Inferred from the GPS Measurement Campaigns
}

\author{
Mashadi Hossainali, M. ${ }^{* 1}$, Heidari H.R. ${ }^{2}$ \\ 1- Assistant Prof., Faculty of Geodesy and Geomatics Engineering, K.N. Toosi University of Technology \\ 2- M.Sc. in Geodesy, Faculty of Geodesy and Geomatics Engineering, K.N. Toosi University of Technology
}

\begin{abstract}
Using the theory of analytical surface deformation analysis, the Earth's vertical surface deformation has been analyzed for Iran. Iran Global GPS campaign is used for the mentioned purpose. This network is the first regional GPS one in Iran which was designed and measured within a scientific cooperation between the National Cartographic Center of Iran and the University of Montpellier in France. The network measurements have been carried out in three successive epochs: 1999, 2001 and 2005. GAMIT/GLOBK GPS processing package has been used for processing the corresponding code and carrier phase measurements. To analyze vertical deformation in Iran, the change in the Gauss's second fundamental form and a measure for the change in curvature, mean curvature here, is used. Using the other available evidences such as focal mechanism solutions of the seismic events which have occurred during the observation period of this study has been verified.
\end{abstract}

Keywords: Deformation analysis, GPS, Analytical deformation analysis, vertical Deformation.

Correspondence Address: Faculty of Geodesy \& Geomatics Engineering, K.N. Toosi University of Techcnology, No. 1346, Vali-asr Ave., Mirdamad Cross, Tehran, Iran. Tel: +982188888445

Email: Hossainali@kntu.ac.ir 